\title{
Inventory Strategies For Systems With Fast \\ Remanufacturing
}

\author{
Ruud Teunter, Erwin van der Laan, Dimitrios Vlachos
}

\begin{tabular}{|l|l|}
\hline \multicolumn{2}{|l|}{ ERIM REPORT SERIES RESEARCH IN MANAGEMENT } \\
\hline ERIM Report Series reference number & ERS-2002-77-LIS \\
\hline Publication & September 2002 \\
\hline Number of pages & 26 \\
\hline Email address corresponding author & elaan@fbk.eur.nl \\
\hline Address & Erasmus Research Institute of Management (ERIM) \\
& Rotterdam School of Management / Faculteit Bedrijfskunde \\
& Erasmus Universiteit Rotterdam \\
& P.O. Box 1738 \\
& 3000 DR Rotterdam, The Netherlands \\
& Phone: $\quad+31104081182$ \\
& Fax: $\quad+31104089640$ \\
& Email: info@erim.eur.nl \\
& Internet: $\quad$ www.erim.eur.nl \\
\hline
\end{tabular}

Bibliographic data and classifications of all the ERIM reports are also available on the ERIM website: www.erim.eur.nl 


\author{
REPORT SERIES
}

RESEARCH IN MANAGEMENT

\begin{tabular}{|c|c|c|}
\hline \multicolumn{3}{|c|}{ BIBLIOGRAPHIC DATA AND CLASSIFICATIONS } \\
\hline Abstract & \multicolumn{2}{|c|}{$\begin{array}{l}\text { We describe hybrid manufacturing/remanufacturing systems with a long lead time for } \\
\text { manufacturing and a short lead time for remanufacturing. We review the classes of inventory } \\
\text { strategies for hybrid systems in the literature. These are all based on equal lead times. For } \\
\text { systems with slow manufacturing and fast remanufacturing, we propose a new class. An } \\
\text { extensive numerical experiment shows that the optimal strategy in the new class almost always } \\
\text { performs better and often much better than the optimal strategies in all other classes. }\end{array}$} \\
\hline \multirow{3}{*}{$\begin{array}{l}\text { Library of Congress } \\
\text { Classification } \\
\text { (LCC) }\end{array}$} & $5001-6182$ & Business \\
\hline & $5201-5982$ & Business Science \\
\hline & HD 9720 & Manufacturing \\
\hline \multirow{4}{*}{$\begin{array}{l}\text { Journal of Economic } \\
\text { Literature } \\
\text { (JEL) }\end{array}$} & M & Business Administration and Business Economics \\
\hline & M 11 & Production Management \\
\hline & R 4 & Transportation Systems \\
\hline & L 6 & Industry Studies: Manufacturing \\
\hline \multirow{4}{*}{$\begin{array}{l}\text { European Business Schools } \\
\text { Library Group } \\
\text { (EBSLG) }\end{array}$} & $85 \mathrm{~A}$ & Business General \\
\hline & $260 \mathrm{~K}$ & Logistics \\
\hline & $240 \mathrm{~B}$ & Information Systems Management \\
\hline & $255 \mathrm{~A} / \mathrm{B}$ & Production and Operations Management \\
\hline \multicolumn{3}{|c|}{ Gemeenschappelijke Onderwerpsontsluiting (GOO) } \\
\hline \multirow[t]{4}{*}{ Classification GOO } & 85.00 & Bedrijfskunde, Organisatiekunde: algemeen \\
\hline & 85.34 & Logistiek management \\
\hline & 85.20 & Bestuurlijke informatie, informatieverzorging \\
\hline & 85.03 & Methoden en Technieken, Operations Research \\
\hline \multirow[t]{3}{*}{ Keywords GOO } & \multicolumn{2}{|c|}{ Bedrijfskunde / Bedrijfseconomie } \\
\hline & \multicolumn{2}{|c|}{ Bedrijfsprocessen, logistiek, management informatiesystemen } \\
\hline & \multicolumn{2}{|c|}{ Productiesystemen, taxonomie, modellen, voorraadbeheer } \\
\hline Free keywords & \multicolumn{2}{|c|}{ Logistics, remanufacturing, stochastic inventory control } \\
\hline
\end{tabular}




\title{
Inventory strategies for systems with fast remanufacturing
}

\author{
Ruud Teunter* Erwin van der Laan ${ }^{\dagger} \quad$ Dimitrios Vlachos ${ }^{\ddagger}$
}

August 7, 2002

\begin{abstract}
We describe hybrid manufacturing/remanufacturing systems with a long lead time for manufacturing and a short lead time for remanufacturing. We review the classes of inventory strategies for hybrid systems in the literature. These are all based on equal lead times. For systems with slow manufacturing and fast remanufacturing, we propose a new class. An extensive numerical experiment shows that the optimal strategy in the new class almost always performs better and often much better than the optimal strategies in all other classes.
\end{abstract}

Keywords: Logistics, remanufacturing, stochastic inventory control

\section{Introduction}

Remanufacturing is the type of recovery that brings a returned product or some if its parts to an 'as-new' condition ${ }^{1}$. Remanufacturing is environmentally friendly and provides a green image. In addition, remanufacturing can be very profitable ${ }^{2}$.

*Erasmus University Rotterdam, Econometric Institute, Burg. Oudlaan 50, PO Box 1738, 3000 DR Rotterdam, The Netherlands. E-mail: teunter@yahoo.com

${ }^{\dagger}$ Erasmus University Rotterdam, Department of Decision and Information Sciences, Burg. Oudlaan 50, PO Box 1738, 3000 DR Rotterdam, The Netherlands. E-mail: elaan@fbk.eur.nl

$¥$ Aristoteles University of Thessaloniki, Department of Mechanical Engineering, 54006 Thessaloniki, Greece. E-mail: vlachos@egnatia.ee.auth.gr 
Items (products or parts) that are remanufactured nowadays include machine tools, medical instruments, copiers, automobile parts, computers, office furniture, mass transit, aircraft, aviation equipment, telephone equipment and tires ${ }^{1-9}$.

Remanufactured parts are sometimes used as service parts. This can be especially attractive if the product itself is no longer manufactured, that is, in the final phase of the service period ${ }^{10}$. In that phase, manufacturing new parts can be expensive and slow, since those parts are no longer needed in large quantities. Hence, especially in the final phase, remanufacturing parts that are disassembled from returned products can be faster and less expensive than manufacturing new parts. In this paper, we will analyse such situations.

We consider a single item hybrid inventory system with manufacturing and remanufacturing. It is assumed that any customer order can be satisfied with either a new or a remanufactured unit. We note that this is not always the case in practice, even if remanufactured units are considered as-good-as-new. A graphical illustration is given in Figure 1.

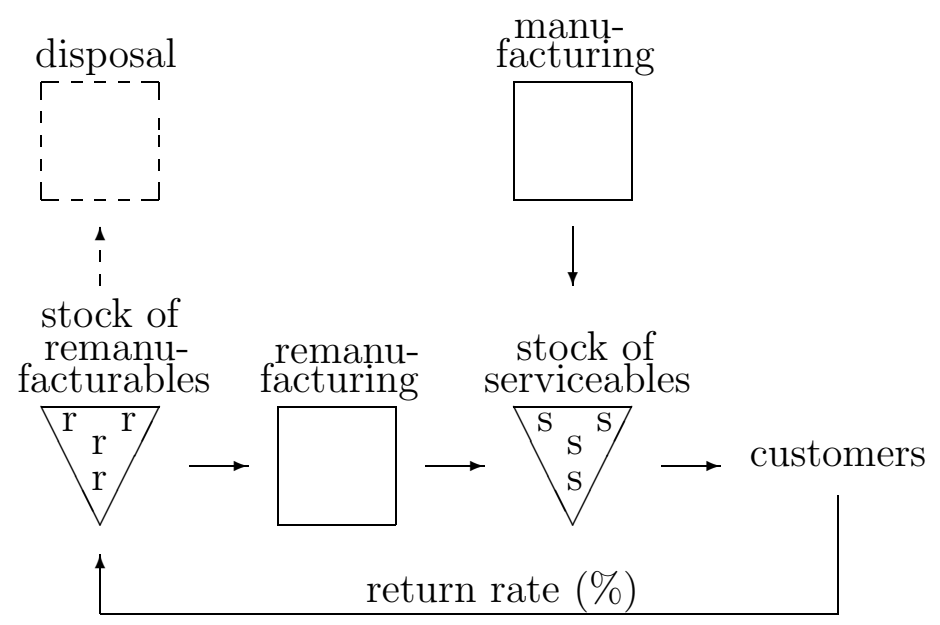

Figure 1: Hybrid inventory system with manufacturing and remanufacturing (and with or without a disposal option for returned remanufacturable items).

Manufacturing is needed since the number of remanufacturable items is insufficient to satisfy all demands, that is, since the recovery rate is less than 1 . We do not include a disposal option for remanufacturable items. Teunter and Vlachos ${ }^{11}$ recently showed 
that such a disposal option is only necessary for extreme cases where the item under consideration is very slow-moving, the recovery rate is high, and remanufacturing is almost as expensive as manufacturing.

We remark that the system is not restricted to the above 'service part example'. Indeed, it is applicable to both product and part remanufacturing, as long as the (expected) lead time for manufacturing is larger than the lead time for remanufacturing, and manufacturing is more expensive than remanufacturing. Our goal is to propose a class of inventory strategies for this single item hybrid inventory system with unequal lead times. This class of strategies should be appropriate for realistic situations with positive lead times, positive set-up costs, and stochastic demand and return.

The remainder of the paper is organised as follows. In Section 2 we review the relevant inventory strategies that have been proposed in the literature for hybrid inventory systems with manufacturing and remanufacturing. We indicate their disadvantages, especially for situations with unequal (expected) lead times. In Section 3 we propose a class of inventory strategies that has not been studied before. These strategies are more appropriate for situations with unequal lead times, as we illustrate numerically in Section 4. We end with some conclusions, a discussion and directions for further research in Section 5.

\section{Previously proposed strategies}

We will only discuss those inventory strategies that are appropriate for models with positive lead times for both manufacturing and remanufacturing (denoted by $L_{m}$ and $L_{r}$, respectively), with positive set-up costs for both manufacturing and remanufacturing, and with stochastic demand and return. These are the Standard PUSH strategy and the Standard PULL strategy proposed by van der Laan et al. ${ }^{12,13}$. and the Lead Time Adjusted PUSH strategy proposed by Inderfurth and van der Laan ${ }^{14}$. All three are continuous review strategies, but they could easily be modified for periodic review models. We refer interested readers to van der Laan ${ }^{12}$ for a review of other strategies (both periodic review and continuous review) proposed in the literature.

The Standard PUSH strategy proposed by van der Laan et al. ${ }^{12,13}$ is characterized by the order level $s_{m}$ for manufacturing, and order quantities $Q_{m}$ for manufacturing and $Q_{r}$ 
for remanufacturing. We remark that alternatively, an order-up-to level for manufacturing instead of an order quantity can be used. That only leads to a different strategy if batch demands can occur. In this paper, we will describe the Standard PUSH strategy and also other strategies in terms of order levels and order quantities.

The Standard PUSH strategy is defined as follows. Remanufacturing starts as soon as the on-hand inventory of remanufacturables reaches $Q_{r}$. So remanufacturables are pushed into the remanufacturing process. Manufacturing starts each time that the serviceable inventory position (serviceable inventory on hand + serviceable inventory on manufacturing order + serviceable inventory on remanufacturing order) drops to (or possibly below for the case of batch demands) $s_{m}$. The Standard PUSH strategy is illustrated in Figure 2 for the case of unit demands and unit returns. Table 1 gives the occurrence times of demands and returns associated with this Figure (and other figures illustrating strategies that will follow), which are chosen arbitrarily.

\begin{tabular}{c|cccccccccccccccc} 
time & 5 & 8 & 11 & 17 & 17.5 & 20 & 26 & 30 & 32 & 37 & 40 & 42 & 43 & 44 & 46 & 48 \\
\hline occurrence & $\mathrm{D}$ & $\mathrm{D}$ & $\mathrm{D}$ & $\mathrm{R}$ & $\mathrm{D}$ & $\mathrm{D}$ & $\mathrm{D}$ & $\mathrm{D}$ & $\mathrm{R}$ & $\mathrm{D}$ & $\mathrm{R}$ & $\mathrm{R}$ & $\mathrm{R}$ & $\mathrm{D}$ & $\mathrm{R}$ & $\mathrm{R}$
\end{tabular}

\begin{tabular}{c|cccccc} 
time & 50.2 & 56 & 59.7 & 60 & 64 & 67 \\
\hline occurrence & $\mathrm{D}$ & $\mathrm{D}$ & $\mathrm{R}$ & $\mathrm{D}$ & $\mathrm{D}$ & $\mathrm{D}$
\end{tabular}

Table 1: Times at which demands $(D)$ and returns $(R)$ occur in Figures 2 - 6. These times are chosen arbitrarily and merely illustrative.

Note that since demand and return are discrete, the serviceable inventory position is always at least $s_{m}+1$ and the on hand inventory of remanufacturables is at most $Q_{r}-1$. (It instantaneously reaches $Q_{r}$.)

The main disadvantage of a Standard PUSH strategy is that it can lead to very high serviceable inventory levels, especially if the return process is very volatile (which it typically is ${ }^{15}$ ). In periods with more returns than demands, pushing all returns through the remanufacturing process causes high levels of serviceable inventory. Furthermore, there is an additional possible overstocking effect if the lead time for remanufacturing is smaller than the lead time for manufacturing. This is explained as follows. The serviceable 


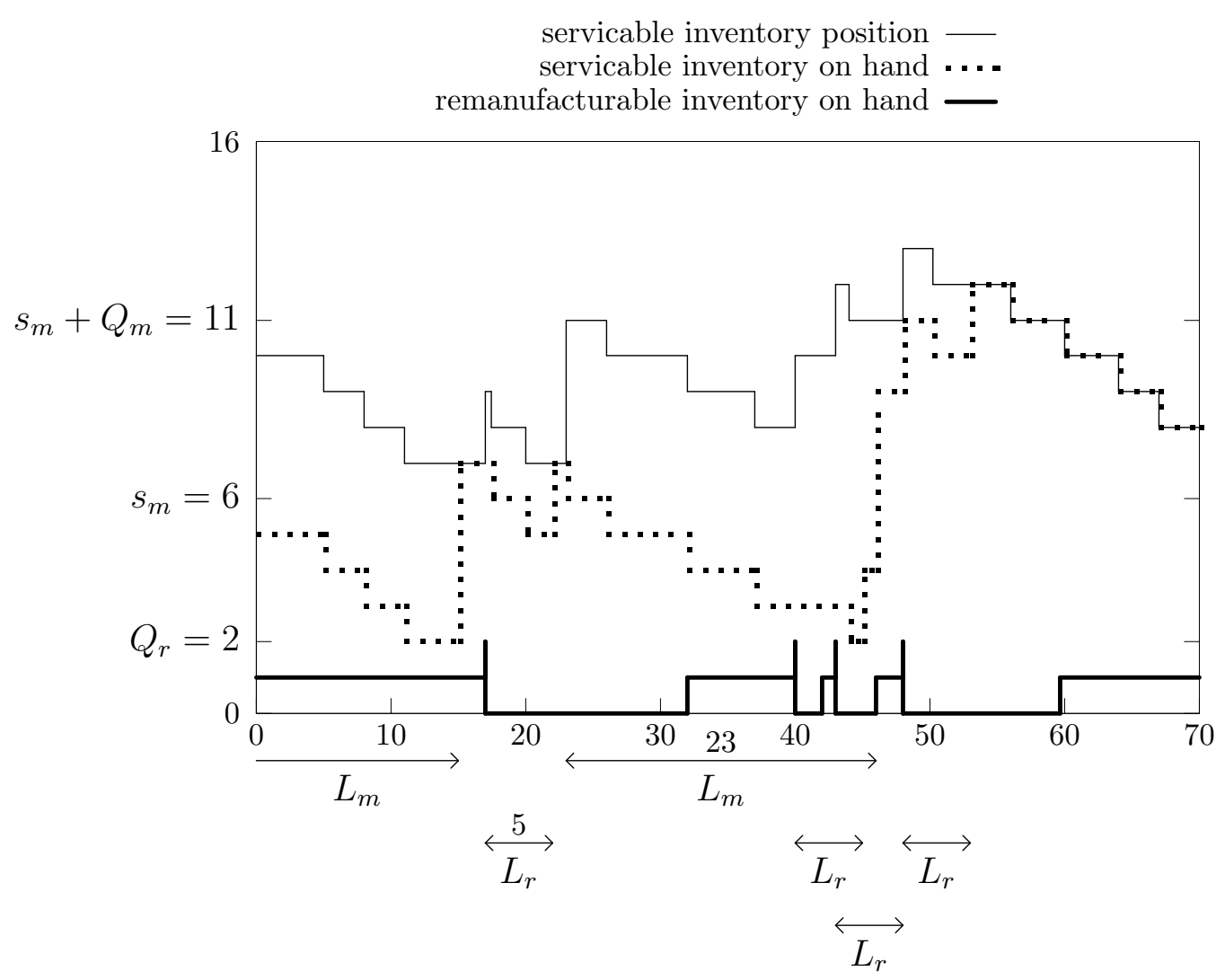

Figure 2: Illustration of the Standard PUSH strategy $\left(s_{m}=6, Q_{m}=5, Q_{r}=2\right)$ if the lead times $L_{m}$ for manufacturing and $L_{r}$ for remanufacturing are respectively 23 and 5.

inventory position is always at least $s_{m}$, which is based on the manufacturing lead time $L_{m}$, when remanufacturing is started. But since the remanufacturing lead time is smaller, a remanufacturing order level (provided there is stock of items ready to be remanufactured) smaller than $s_{m}$ would be sufficient. See also Figure 2 .

The Lead Time Adjusted PUSH strategy proposed by Inderfurth and van der Laan ${ }^{14}$ diminishes the additional overstocking effect by using an "effective" lead time $l_{r}$ larger than the actual lead time $L_{r}$ for remanufacturing. As soon as $Q_{r}$ remanufacturables become available, they enter the modified inventory position immediately, but remanufacturing will start $l_{r}-L_{r}$ time units later. This is illustrated in Figure 3.

Intuition suggests that the additional overstocking effect is minimized by setting $l_{r}$ (approximately) equal to $L_{m}$. Indeed, that turned out to be optimal in many of the numerical experiments that we considered. However, in some of the experiments the optimal value for $l_{r}$ was much smaller than $L_{m}$, sometimes closer to $L_{r}$. This is explained by the main disadvantage of simply using larger effective remanufacturing lead time; it 


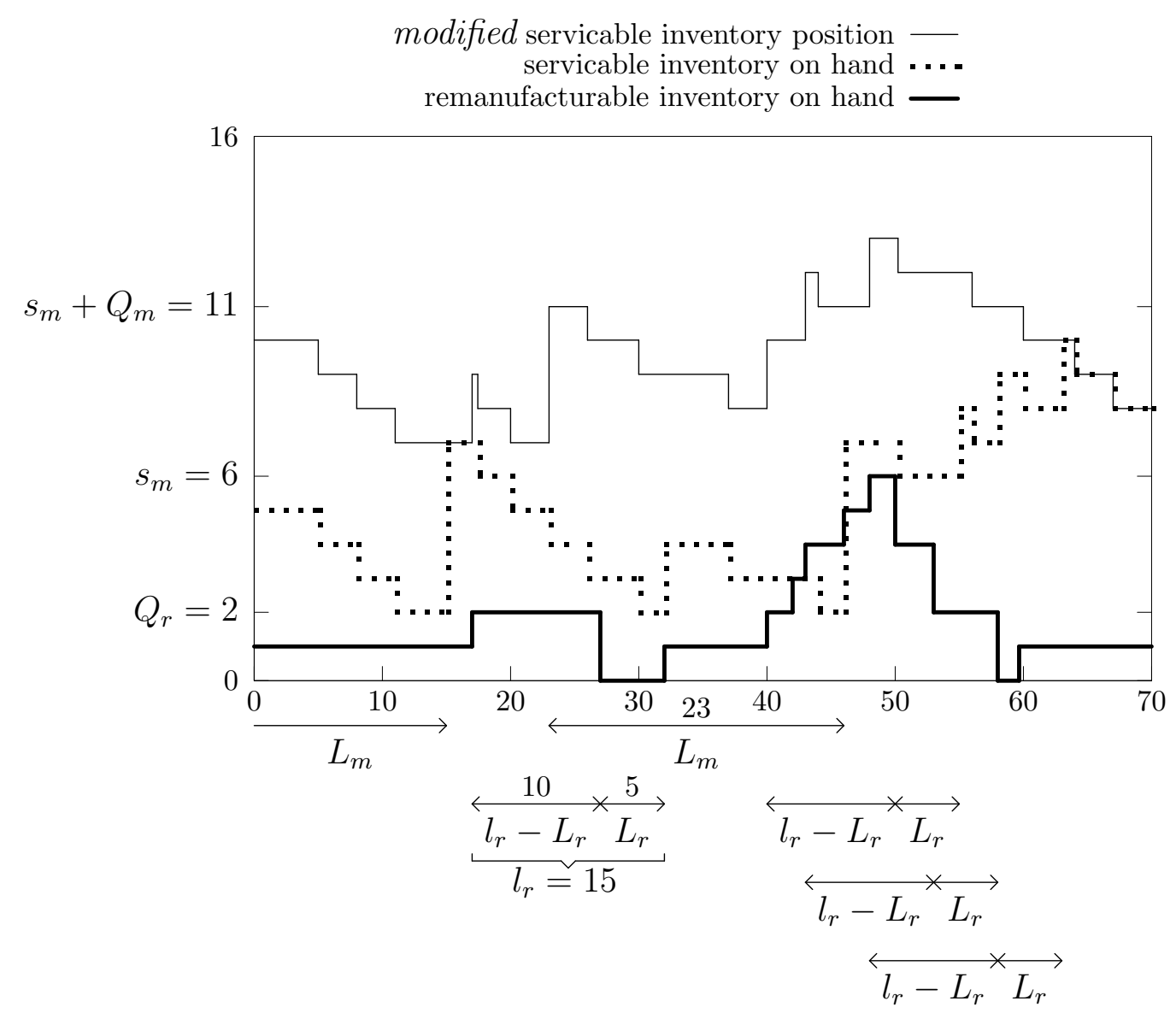

Figure 3: Illustration of the Lead Time Adjusted PUSH strategy $\left(s_{m}=6, Q_{m}=5, Q_{r}=2, l_{r}=\right.$ $15)$ if the lead times $L_{m}$ for manufacturing and $L_{r}$ for remanufacturing are respectively 23 and 5 , and the effective remanufacturing lead time is $l_{r}=15$. When $Q_{r}$ or more remanufacturables become available, they enter the modified inventory position immediately, but remanufacturing will start $l_{r}-L_{r}$ time units later.

provides no mechanism to quickly react to changes in the demand rate.

Another disadvantage of the Lead Time Adjusted PUSH strategy is that, as for the Standard PUSH strategy, periods with more returns than demands still lead to overstocking. Figure 3 illustrates this. A practical disadvantage of the Lead Time Adjusted PUSH strategy is that including remanufacturables which are not yet being remanufactured in the serviceable inventory position is possibly confusing.

Based on the above mentioned disadvantages of the Standard PUSH strategy and the Lead Time Adjusted PUSH strategy, it may be better to use a strategy that pulls remanufacturables into the remanufacturing process. The Standard PULL strategy proposed by van der Laan et al. ${ }^{12,13}$ is characterized by order levels $s_{m}$ for manufacturing and $s_{r}$ for 
remanufacturing, and order quantities $Q_{m}$ for manufacturing and $Q_{r}$ for remanufacturing. It is restricted by $s_{r} \geq s_{m}$, as we will explain below, and defined as follows. Remanufacturing starts whenever the serviceable inventory position is at (or below) $s_{r}$, and $Q_{r}$ remanufacturables are available. Manufacturing starts each time that the serviceable inventory position drops to or below $s_{m} \leq s_{r}$. For the special case that $s_{m}=s_{r}$, priority is given to remanufacturing if the serviceable inventory position drops to (or below) $s_{m}=s_{r}$ and $Q_{r}$ remanufacturables are available. This strategy is illustrated in Figure 4. Note that the Standard PUSH strategy is a special case of the Standard PULL strategy with $s_{r}=\infty$ (or $s_{r}$ large enough).

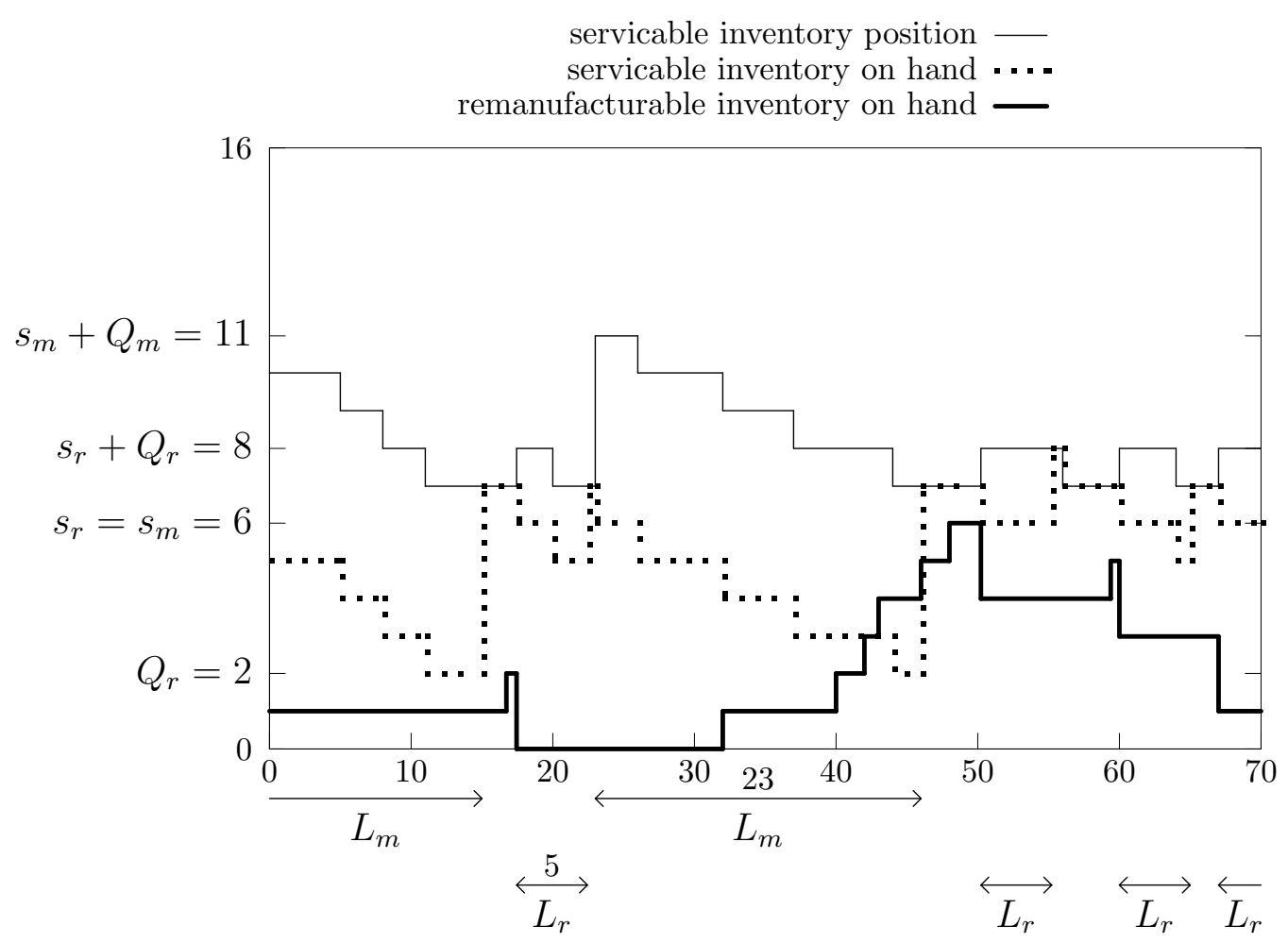

Figure 4: Illustration of the Standard PULL strategy $\left(s_{m}=6, Q_{m}=5, s_{r}=6, Q_{r}=2\right)$ if the lead times $L_{m}$ for manufacturing and $L_{r}$ for remanufacturing are respectively 23 and 5.

It is important to remark that this class of strategies is restricted by $s_{r} \geq s_{m}$. Otherwise, starting with more than $s_{m}$ serviceables in stock, the serviceable inventory position never drops below $s_{m}>s_{r}$ and hence remanufacturing is never started. Due to this order level restriction, the Standard PULL strategy suffers from the same overstocking effect (previously referred to as the additional overstocking effect) as the Standard PUSH strat- 
egy. In the next section, we will therefore propose two different classes of pull strategies.

\section{A modified and a new class of PULL strategies}

The 'delayed lead time' modification that was proposed by Inderfurth and van der Laan ${ }^{14}$ for the Standard PUSH strategy (and discussed in the previous section) can also be applied to the Standard PULL strategy. The Lead Time Adjusted PULL strategy is characterized by order levels $s_{m}$ for manufacturing and $s_{r}$ for remanufacturing, order quantities $Q_{m}$ for manufacturing and $Q_{r}$ for remanufacturing, and by the effective remanufacturing lead time $l_{r} \geq L_{r}$. See Figure 5 .

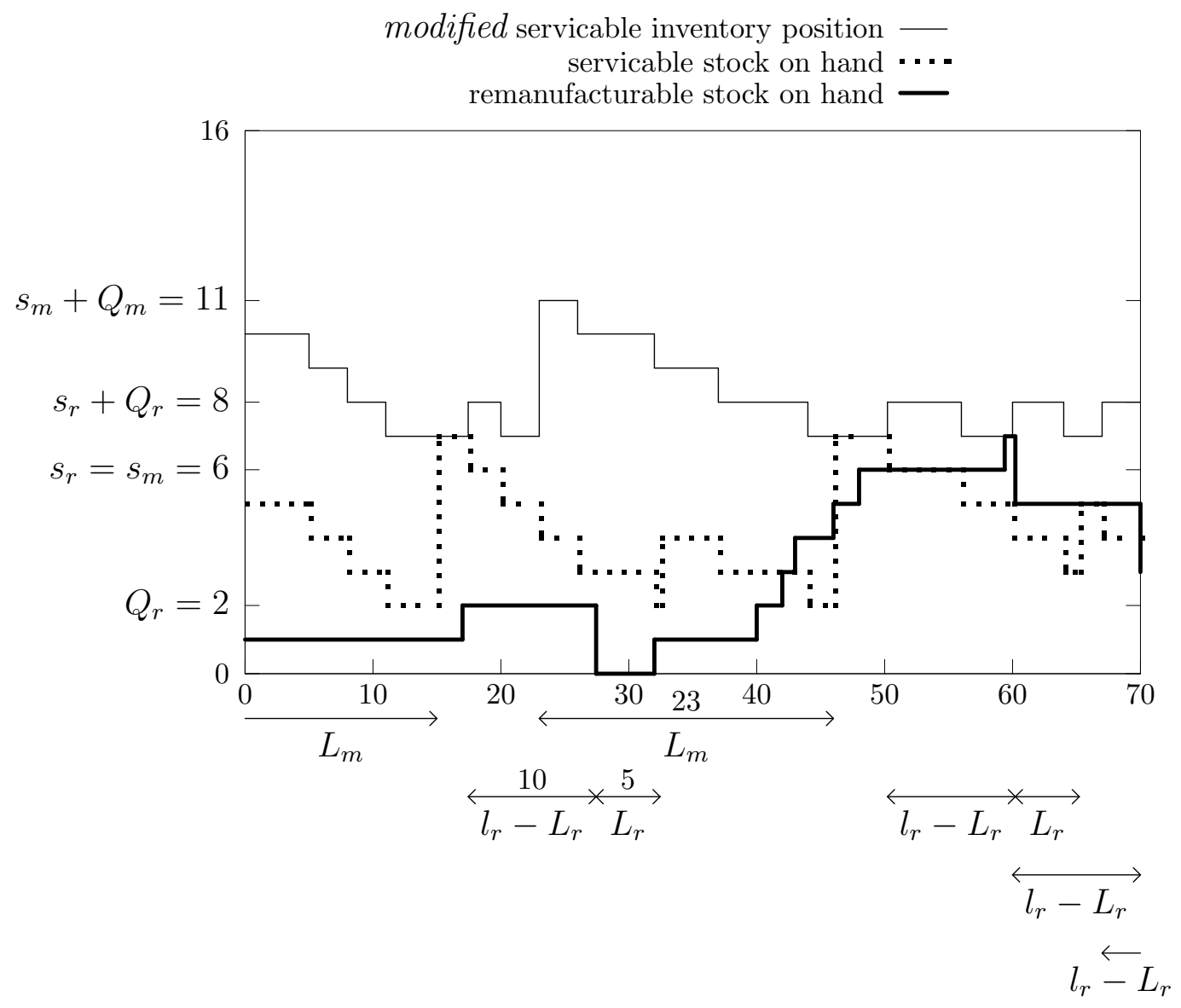

Figure 5: Illustration of the Lead Time Adjusted PULL strategy $\left(s_{m}=6, Q_{m}=5, s_{r}=6, Q_{r}=\right.$ $\left.2, l_{r}=15\right)$ if the lead times $L_{m}$ for manufacturing and $L_{r}$ for remanufacturing are respectively 23 and 5, and the effective remanufacturing lead time is $l_{r}=15$. When a remanufacturing order is placed, the ordered items enter the modified inventory position immediately, but remanufacturing will start $l_{r}-L_{r}$ time units later. 
Unfortunately, the Lead Time Adjusted PULL strategy suffers from the same loss of demand flexibility as the Lead Time Adjusted PUSH strategy. The larger effective lead time for remanufacturing reduces the ability to react swiftly to changes in the demand rate (see the previous section).

We therefore propose a new class of PULL strategies. We call them "Separate PULL" strategies, since they separate manufacturing decisions and remanufacturing decisions as much as possible. The underlying logic is that long-term manufacturing decisions should control the total stock in the system (serviceable inventory position plus remanufacturables), while short-term remanufacturing decisions should control the serviceable stock on hand plus on order with remaining lead time at most $L_{r}$.

The "Separate PULL" strategies are characterized by order levels $s_{m}$ for manufacturing and $s_{r}$ for remanufacturing, and order quantities $Q_{m}$ for manufacturing and $Q_{r}$ for remanufacturing. They are defined as follows. Manufacturing is started when the total inventory position (remanufacturable inventory on hand + serviceable inventory on hand + serviceable inventory on manufacturing order + serviceable inventory on remanufacturing order) drops to or below $s_{m}$. Remanufacturing starts whenever the serviceable remanufacturing inventory position (serviceable inventory on hand + serviceable inventory on manufacturing order with a remaining lead time of at most $L_{r}+$ serviceable inventory on remanufacturing order) is at (or below) $s_{r}$, and $Q_{r}$ remanufacturables are available. This strategy is illustrated in Figure 6. The definitions of the inventory positions are summarised in Table 2.

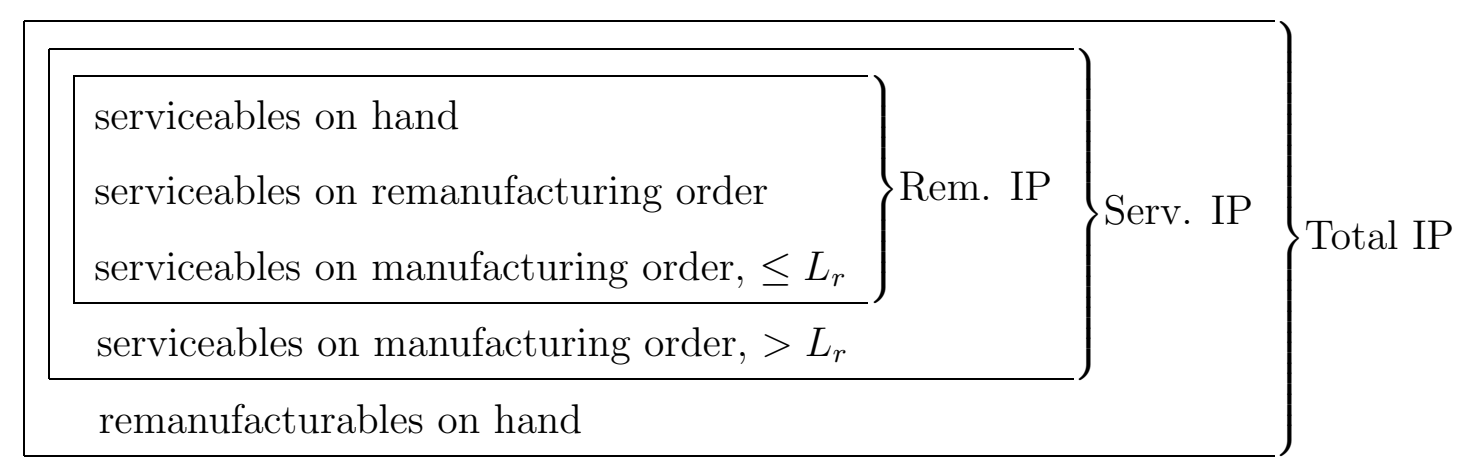

Table 2: Definitions of the Remanufacturable, Servicable, and Total Inventory Positions. 


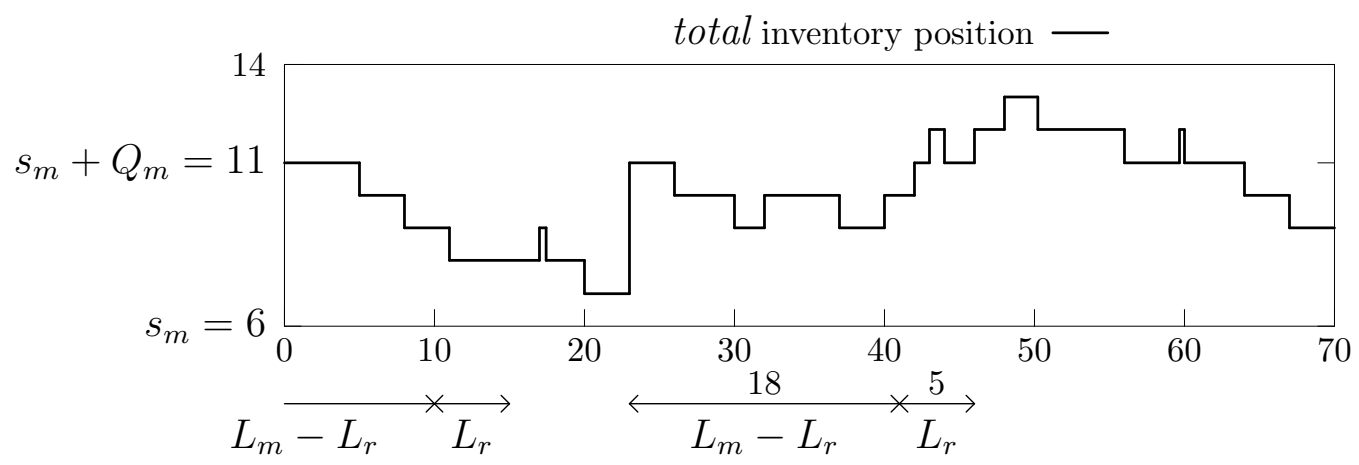

servicable inventory on hand + on order with remaining lead time at most $L_{r}$ servicable inventory on hand .... remanufacturable inventory on hand

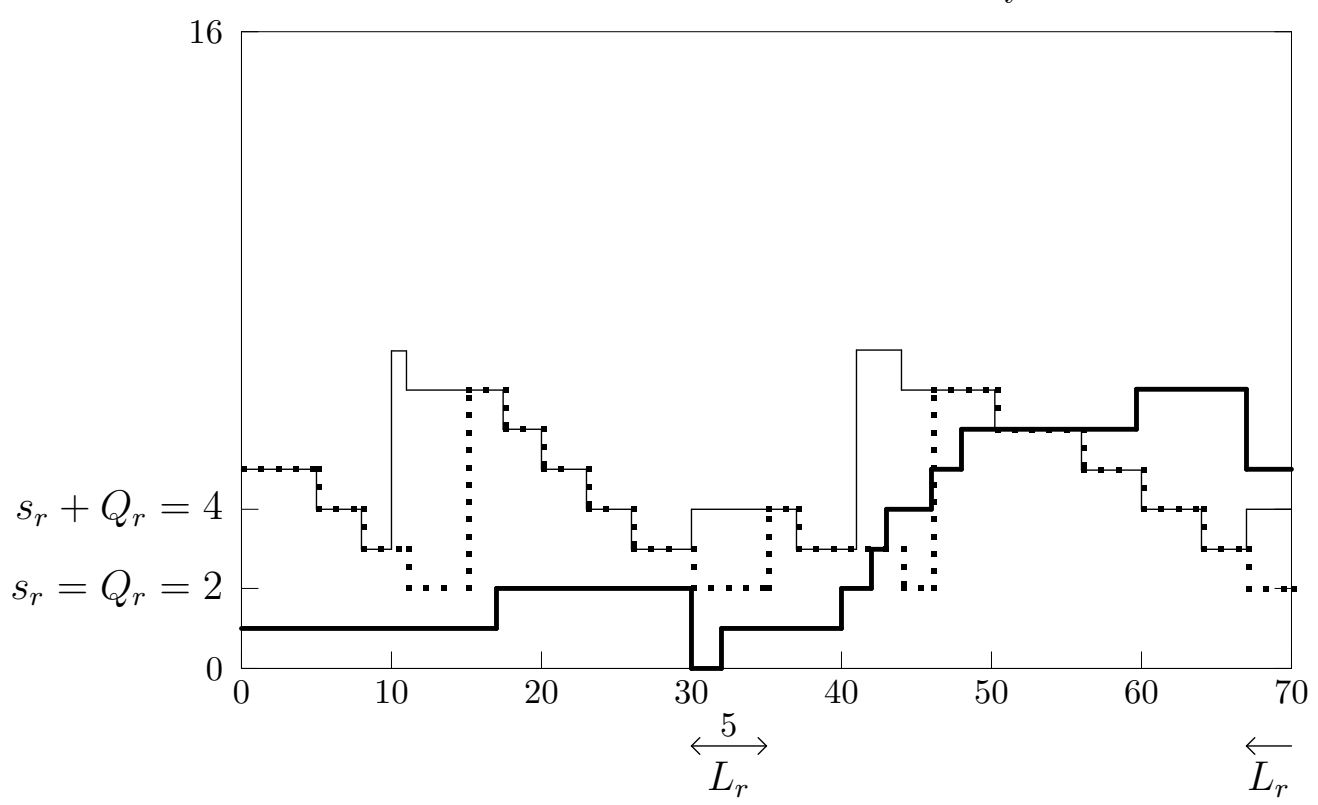

Figure 6: Illustration of the Separate PULL strategy $\left(s_{m}=6, Q_{m}=5, s_{r}=2, Q_{r}=2\right)$ if the lead times $L_{m}$ for manufacturing and $L_{r}$ for remanufacturing are respectively 23 and 5 . The total inventory position includes remanufacturable inventory on hand, serviceable inventory on hand, serviceable inventory on manufacturing order and serviceable inventory on remanufacturing order, i.e., all items in the system. 
Note that the total inventory position is not influenced by remanufacturing decisions, since it includes remanufacturables on hand. The reason for including remanufacturables on hand, when deciding whether or not to start a manufacturing batch, is that those items can be remanufactured to serviceable items before a new manufacturing batch arrives. For the same reason, serviceables on manufacturing order with a remaining lead time of more than $L_{r}$ are not considered when deciding whether or not to start a remanufacturing batch.

In the next section, we shall numerically compare the optimal strategies in the classes Standard PUSH, Lead Time Adjusted PUSH, Standard PULL, Lead Time Adjusted PULL and Separate PULL in an extensive experiment.

We end this section with a reference to recent work of Kiesmüller et al. ${ }^{16,17}$. She studies the periodic review (discrete time) variant of our inventory system, but restricts the analysis to the special case with zero set-up costs for both manufacturing and remanufacturing. She proposes a class of strategies which is a subclass of the Separate PULL strategies with order quantities equal to one (applied in a periodic review setting). In Kiesmüller et al. ${ }^{16}$, the optimal strategy in this subclass is compared to the optimal strategy in the Standard PULL class for some examples. The reported cost savings vary between $0 \%$ and $30 \%$ and depend mainly on the difference in lead time. In Kiesmüller et al. ${ }^{17}$, the focus is on finding simple formulae that determine near-optimal order levels for the subclass of Separate PULL strategies. In that paper, no comparison is made with other classes of strategies.

The numerical experiment discussed in the next section is much more extensive. Moreover, we study a more general class of Separate PULL strategies (in a continuous review setting) and compare it to all different classes of previously proposed (and adjusted) strategies.

\section{Numerical comparison of strategies}

This section reports on a number of numerical comparisons based on the fifteen examples in Table 3. That table includes the lead times, all relevant costs, and a description of the demand and return processes. The time unit is one day. Each example consists of 
12 scenarios that differ in the manufacturing lead time $L_{m}=10,20,30, \ldots, 120$. The remanufacturing lead time $L_{r}$ is fixed at 10 days, so that $L_{m} \geq L_{r}$ for all scenarios. The cost notations are as follows: holding cost $h_{r}$ for items in the remanufacturable stock (per item per day), holding cost $h_{s}$ for items in the serviceable stock (per item per day), backorder cost $p$ (per item per day), ordering cost $K_{m}$ for manufacturing (per order), and ordering cost $K_{r}$ for remanufacturing (per order). For a discussion on how to set the holding cost rates in a system with remanufacturing, we refer interested readers to Teunter et al. ${ }^{18}$. The mean demand per day is denoted by $\mu_{D}$ and is 1 item for all scenarios. The mean return per day is denoted by $\mu_{R}$ and is either 0.7 or 0.9 items. So the return percentage is either $70 \%$ or $90 \%$.

\begin{tabular}{|c|c|c|c|c|c|c|c|c|c|c|c|}
\hline \multirow[t]{3}{*}{ Ex. } & \multicolumn{2}{|c|}{ lead times } & \multicolumn{5}{|c|}{ costs } & \multicolumn{2}{|c|}{ demand process } & \multicolumn{2}{|c|}{ return process } \\
\hline & \multirow[b]{2}{*}{$L_{r}$} & \multirow[b]{2}{*}{$L_{m}$} & \multicolumn{3}{|c|}{ per year } & \multicolumn{2}{|c|}{ per order } & \multirow[t]{2}{*}{ type } & \multirow{2}{*}{$\begin{array}{l}\text { mean } \\
\mu_{D}\end{array}$} & \multirow[t]{2}{*}{ type } & \multirow{2}{*}{$\begin{array}{l}\text { mean } \\
\mu_{R}\end{array}$} \\
\hline & & & $365 h_{r}$ & $365 h_{s}$ & $365 p$ & $K_{m}$ & $K_{r}$ & & & & \\
\hline 1 & 10 & $10-120$ & 0.001 & 0.1 & 5 & 0.5 & 0.5 & unit Poisson & 1 & unit Poisson & 0.7 \\
\hline 2 & 10 & $10-120$ & 0.05 & 0.1 & 5 & 0.5 & 0.5 & unit Poisson & 1 & unit Poisson & 0.7 \\
\hline 3 & 10 & $10-120$ & 0.1 & 0.1 & 5 & 0.5 & 0.5 & unit Poisson & 1 & unit Poisson & 0.7 \\
\hline 4 & 10 & $10-120$ & 0.001 & 0.1 & 5 & 0.5 & 0.5 & unit Poisson & 1 & unit Poisson & 0.9 \\
\hline 5 & 10 & $10-120$ & 0.05 & 0.1 & 5 & 0.5 & 0.5 & unit Poisson & 1 & unit Poisson & 0.9 \\
\hline 6 & 10 & $10-120$ & 0.1 & 0.1 & 5 & 0.5 & 0.5 & unit Poisson & 1 & unit Poisson & 0.9 \\
\hline 7 & 10 & $10-120$ & 0.001 & 0.1 & 5 & 0.5 & 0.5 & unit Poisson & 1 & batch Poisson & 0.7 \\
\hline 8 & 10 & $10-120$ & 0.05 & 0.1 & 5 & 0.5 & 0.5 & unit Poisson & 1 & batch Poisson & 0.7 \\
\hline 9 & 10 & $10-120$ & 0.1 & 0.1 & 5 & 0.5 & 0.5 & unit Poisson & 1 & batch Poisson & 0.7 \\
\hline 10 & 10 & $10-120$ & 0.001 & 0.1 & 5 & 0.5 & 0.5 & unit Poisson & 1 & batch Poisson & 0.9 \\
\hline 11 & 10 & $10-120$ & 0.05 & 0.1 & 5 & 0.5 & 0.5 & unit Poisson & 1 & batch Poisson & 0.9 \\
\hline 12 & 10 & $10-120$ & 0.1 & 0.1 & 5 & 0.5 & 0.5 & unit Poisson & 1 & batch Poisson & 0.9 \\
\hline 13 & 10 & $10-120$ & 0.001 & 0.1 & 5 & 0 & 0 & unit Poisson & 1 & unit Poisson & 0.9 \\
\hline 14 & 10 & $10-120$ & 0.05 & 0.1 & 5 & 0 & 0 & unit Poisson & 1 & unit Poisson & 0.9 \\
\hline 15 & 10 & $10-120$ & 0.1 & 0.1 & 5 & 0 & 0 & unit Poisson & 1 & unit Poisson & 0.9 \\
\hline
\end{tabular}

Table 3: Model parameters for Examples 1-15. Note that the time unit is one day, so that $365 h_{r}, 365 h_{s}$ and $365 p$ represent the costs per year. For the examples with batch (compound) Poisson returns, the number of returned items is discrete and uniformly distributed between 1 and 20 (i.e. each number has probability 0.05).

For each of the $15 \times 12$ scenarios, the optimal strategies of types Standard PUSH, Standard PULL, 
Lead Time Adjusted PUSH, Lead Time Adjusted PULL, and Separate PULL are determined by combining simulation and grid search (500 runs of 10,000 time units for each strategy, common random numbers). In the remainder of this section, we summarise the results. For ease of notation, we refer to the optimal strategy of each type simply as the strategy of that type.

Figures 7 - 11 graphically represent the cost associated with each type of strategy for all $15 \times 12$ scenarios.

In Example 1 we have a relatively low value of the holding cost rate for remanufacturables $(0.001$ against 0.1 for serviceables) which gives room for the Lead Time Adjusted PUSH and PULL strategies to significantly improve the performance of their 'standard' counterparts. Initially, the Lead Time Adjusted PULL strategy outperforms all other strategies until the manufacturing lead time increases past 60 and the Separate PULL takes over. As the holding cost rate for remanufacturables increases (Examples 2 and 3) all five strategies move closer towards each other, since it pays off less and less to delay remanufacturing orders. In the special case that $h_{r}=h_{s}$, the PUSH and PULL strategies are identical so that their performance is exactly the same (Example 3). See also Table 4.

\begin{tabular}{c|rrrrrrrrrrrr} 
& \multicolumn{11}{c}{ Manufacturing lead time $L_{m}$} \\
Example & 10 & 20 & 30 & 40 & 50 & 60 & 70 & 80 & 90 & 100 & 110 & 120 \\
\hline 1 & 10 & 18 & 29 & 40 & 50 & 59 & 69 & 81 & 90 & 99 & 110 & 120 \\
2 & 10 & 17 & 30 & 34 & 10 & 10 & 10 & 10 & 10 & 10 & 10 & 10 \\
3 & 10 & 10 & 10 & 10 & 10 & 10 & 10 & 10 & 10 & 10 & 10 & 10
\end{tabular}

Table 4: Value of $l_{r}$ for the optimal Lead Time Adjusted PULL strategy in Examples 1-3.

It is observed that the Separate PULL strategy generally performs better than all other strategies as long as the holding cost rate for remanufacturables (compared to that for serviceables) is not too small and the manufacturing lead time is at least twice as large as the remanufacturing lead time. The same results hold for the case that the return percentage equals $90 \%$ (Examples 4-6). In fact, for these examples the Separate PULL strategy outperforms all other strategies for almost all values of the holding cost rates and manufacturing lead time. We observe similar patterns for batch returns (Examples 7-12) and zero fixed costs (Examples 13-15). Note from Examples 13 and 14 that the cost advantage of using the separate PULL strategy can be enormous. It leads to savings of up to $30 \%$ if $h_{r}=0.05\left(h_{s}=0.1\right)$ and even more than $100 \%$ if $h_{r}=0$. These savings are larger than those for examples with non-zero fixed costs (and the same holding cost rates). This shows that the five strategies mainly differ in the way that they balance backorder and holding costs, by using different order levels (and inventory definitions). Indeed, recall that we introduced the separate PULL strategy for this reason. The optimal order quantities balance set-up costs and holding costs, and are comparable for all strategies. So in examples with positive set-up costs, these approximately equal extra costs disguise the poor 'order level performance' of the Standard and the Lead Time Adjusted PUSH and PULL strategies. 


\subsection{The 'wavy' behaviour}

The 'wavy' behaviour of the optimal costs resulting from the standard PUSH and PULL strategies in Examples 1-6 is due to the batching of remanufacturing orders. During a manufacturing lead time, remanufacturing batches come in and help protect against lead time demand. Since remanufacturing orders can cross manufacturing orders, the number of incoming batches is uncertain at the time of placing a manufacturing order. This uncertainty is minimized by choosing $Q_{r}$ such that the average number of incoming remanufacturing batches during a period of length $L_{m}$ equals some integer $n=1,2, \ldots$, i.e. by setting

$$
\frac{L_{m} \mu_{R}}{Q_{r}}=n, \quad \text { or } \quad Q_{r}=\frac{L_{m} \mu_{R}}{n} .
$$

To see this, first consider the PUSH strategy when the return process is deterministic (fixed time between returns). If $n<\frac{L_{m} \mu_{R}}{Q_{r}}<n+1$ then either $n$ or $n+1$ batches can come in during a manufacturing lead time. For small values of $n$, this implies that the relative variation in the number of incoming batches is large. The variation is no longer present if $\frac{L_{m} \mu_{R}}{Q_{r}}=n$, since then exactly $n$ remanufacturing batches will always come in.

Next consider the PUSH strategy when the return process is stochastic. Then it is no longer possible to take away all the variation by setting $Q_{r}=\frac{L_{m} \mu_{R}}{n}$. However, setting $Q_{r}$ in that way does minimize the variation, as is illustrated in Figure 12.

Now consider the PULL strategy when the return process is stochastic. The above arguments for explaining the wavy behaviour still hold to some extent, since the number of remanufacturing batches during a manufacturing lead time is still uncertain, and the average number is also unchanged. However, the number of incoming batches now depends on the demand realizations during the first $L_{m}-L_{r}$ time units of a manufacturing lead time. Depending on whether there are many or few demands, more or less remanufacturables are pulled into the system. As a result, setting $Q_{r}=\frac{L_{m} \mu_{R}}{n}$ in order to control the number of incoming remanufacturing batches is less effective for PULL strategies, especially if $s_{r}$ is close to $s_{m}$ (recall that the class of PULL strategies are restricted by $s_{m} \leq s_{r}$ ). As the difference $s_{r}-s_{m}$ increases, a PULL strategy starts to behave more and more like a PUSH strategy, and the wavy behaviour is more apparent. As is expected, this happens if $h_{r}$ increases (compare Examples 1-3).

As we expect, the wavy behaviour disappears completely if fixed ordering costs are zero and no batching occurs at all (Examples 13-15). If batch returns are introduced (Examples 7-12) the interoccurrence times of remanufacturing batches are much more variable and the wavy effect is less prominent.

Finally, we explain why the wavy behaviour is observed sometimes but not always for the Lead Time Adjusted PUSH and PULL strategy. Those strategies typically (in most scenarios) either adjust the remanufacturing lead time so that it is close to the manufacturing lead time $\left(l_{r} \approx L_{m}\right)$, or do not adjust the lead time at all $\left(l_{r}=L_{r}\right)$. (see Table 4 ). The wavy behaviour disappears if $l_{r} \approx L_{m}$, since then (delayed) remanufacturing orders seldom cross manufacturing orders. 
Example 1: $h_{r}=0.001, r=0.7, K_{m}=K_{r}=0.5$, unit returns

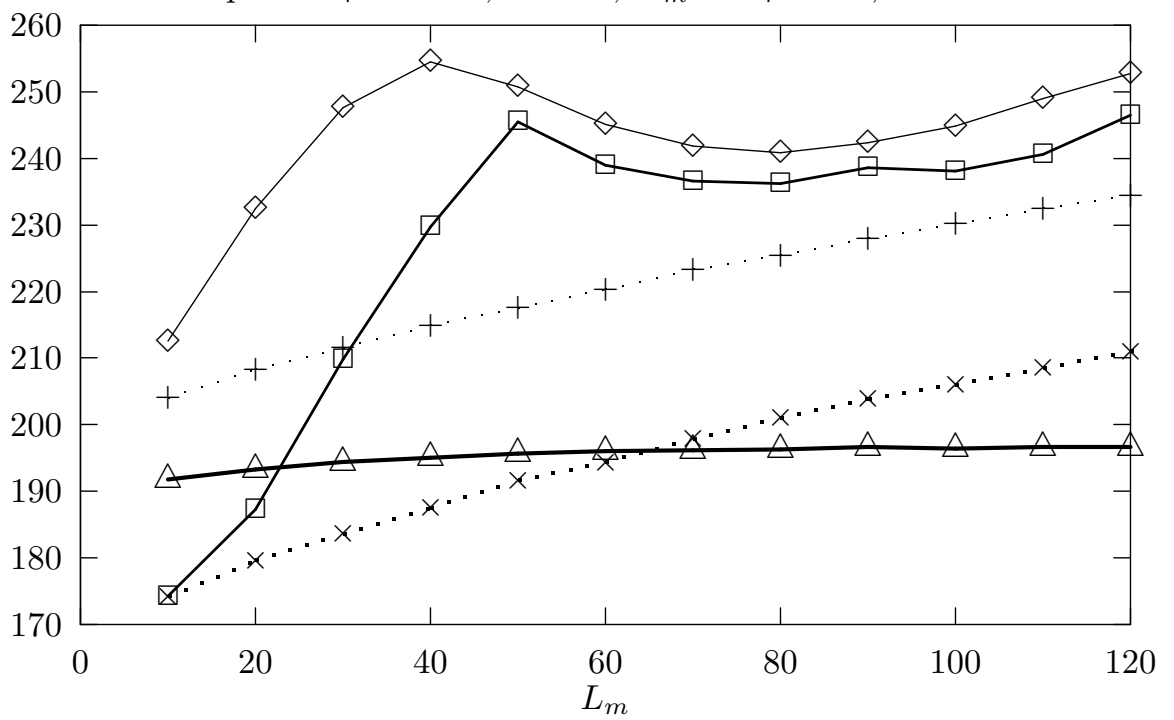

Example 2: $h_{r}=0.05, r=0.7, K_{m}=K_{r}=0.5$, unit returns

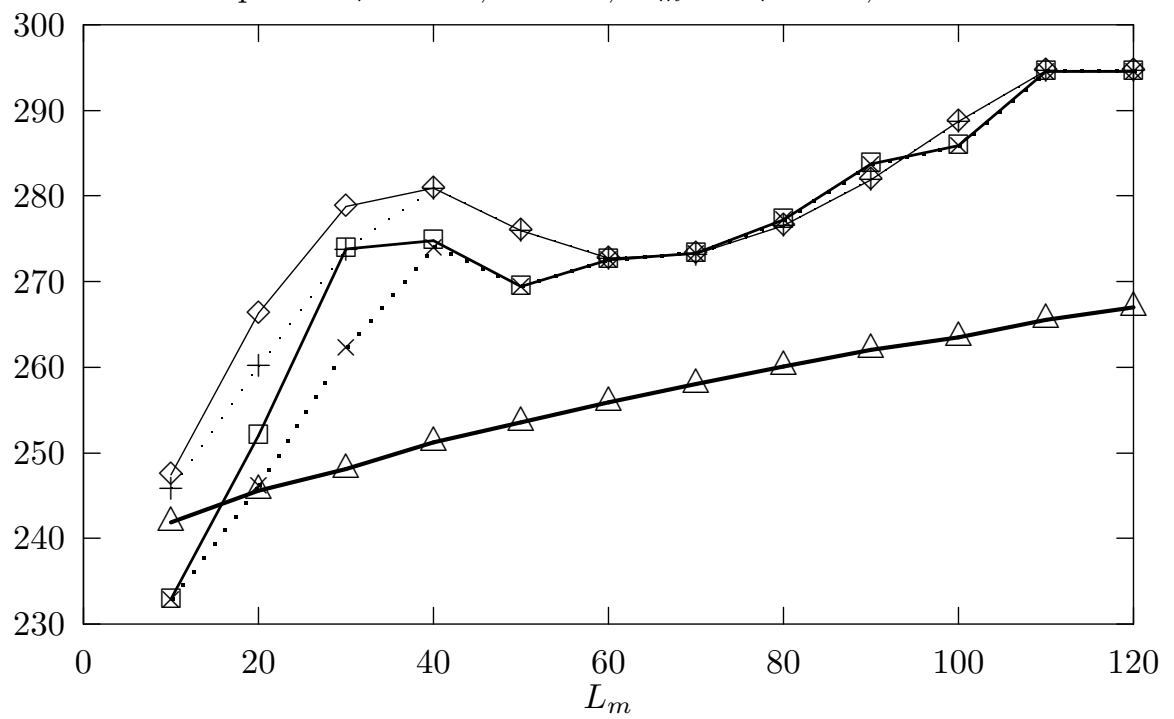

Example 3: $h_{r}=0.1, r=0.7, K_{m}=K_{r}=0.5$, unit returns

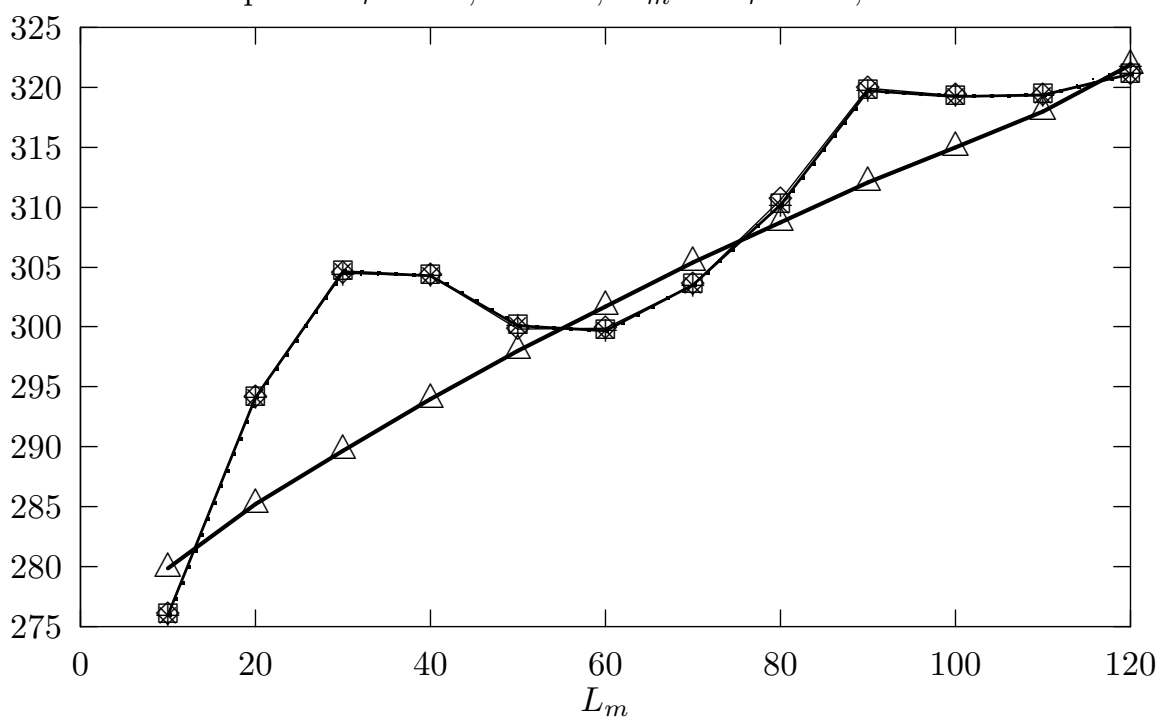

Standard PUSH $\diamond$ LT Adj. PUSH +. Standard PULL $\square$ LT Adj. PULL $\cdot \times \cdot \cdot$ Separate PULL $\triangle$

Standard PUSH $\diamond$ LT Adj. PUSH + Standard PULL $\square$ LT Adj. PULL $\cdot \times \cdot$ Separate PULL $\triangle$

Standard PUSH $\diamond$ LT Adj. PUSH +. Standard PULL $\square$ LT Adj. PULL $\cdot \times \cdot \cdot$ Separate PULL $\triangle$

Figure 7: Average costs for Examples 1-3. See Table 3 for a complete description of the model parameters. 
Example 4: $h_{r}=0.001, r=0.9, K_{m}=K_{r}=0.5$, unit returns

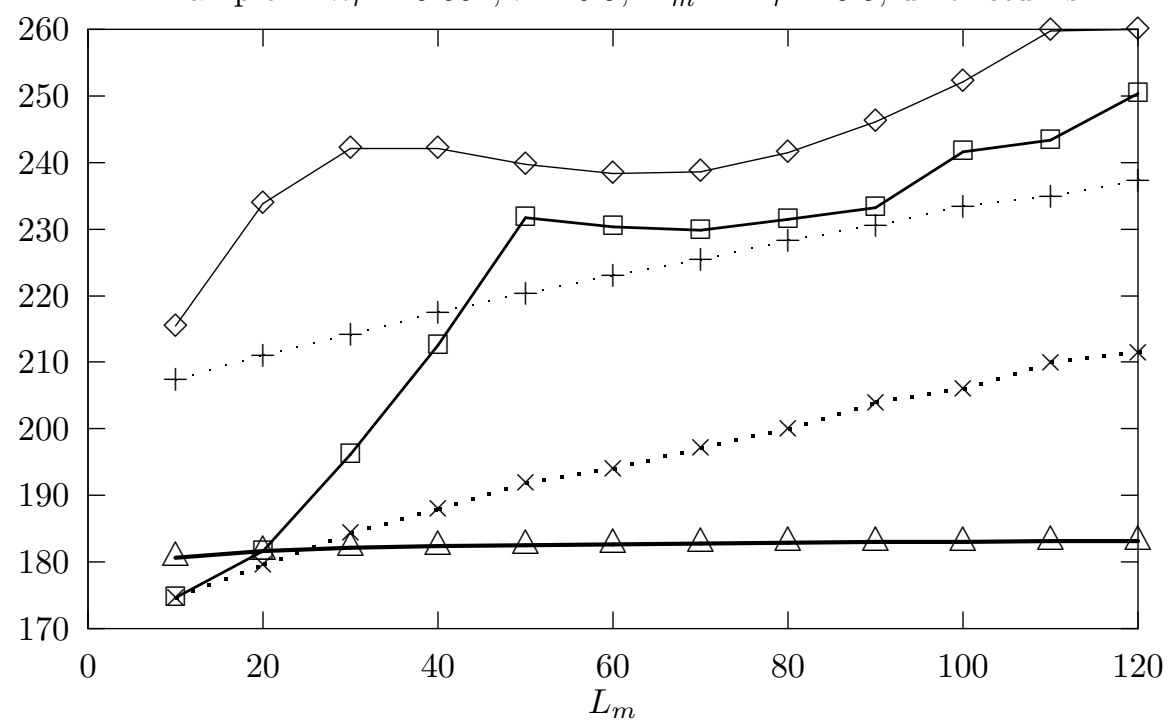

Example 5: $h_{r}=0.05, r=0.9, K_{m}=K_{r}=0.5$, unit returns

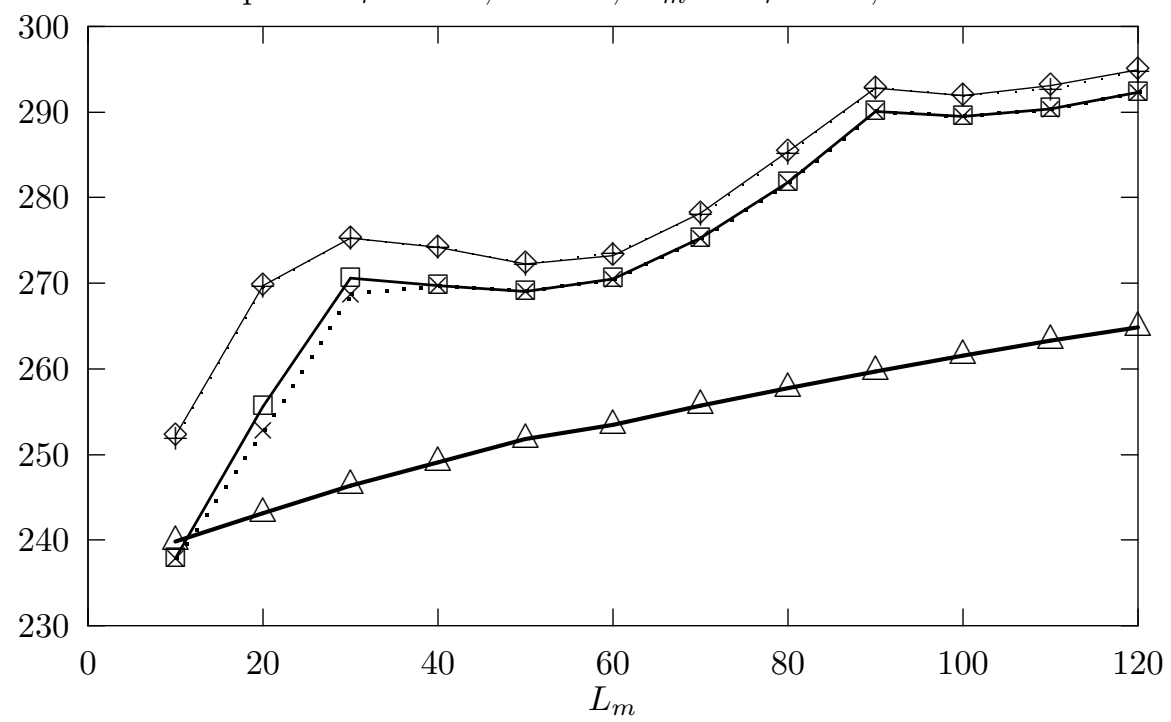

Example 6: $h_{r}=0.1, r=0.9, K_{m}=K_{r}=0.5$, unit returns

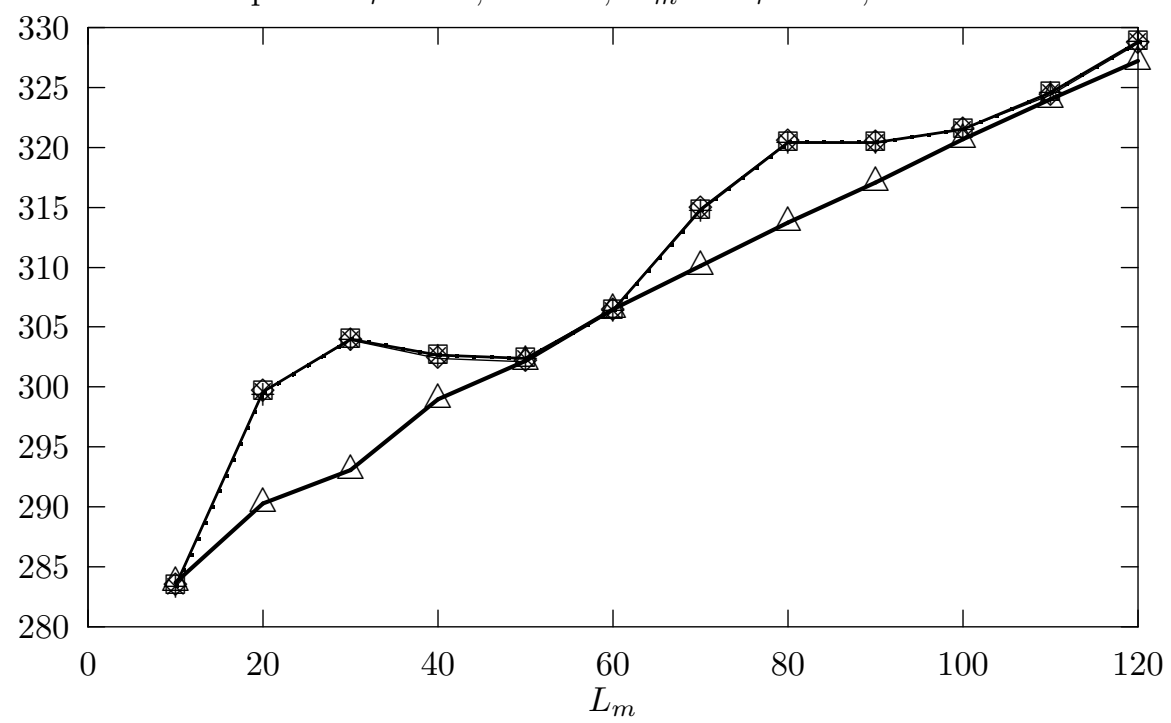

Standard PUSH $\diamond$ LT Adj. PUSH +... Standard PULL — LT Adj. PULL $\cdot \times$. Separate PULL $\triangle$

Standard PUSH $\diamond$ LT Adj. PUSH +. Standard PULL $\square$ LT Adj. PULL $\cdot \times \cdot-$ Separate PULL $\triangle$

Standard PUSH $\diamond$ LT Adj. PUSH +. Standard PULL $\square$ LT Adj. PULL $\cdot \times$. Separate PULL $\_$

Figure 8: Average costs for Examples 4-6. See Table 3 for a complete description of the model parameters. 
Example 7: $h_{r}=0.001, r=0.7, K_{m}=K_{r}=0.5$, batch returns

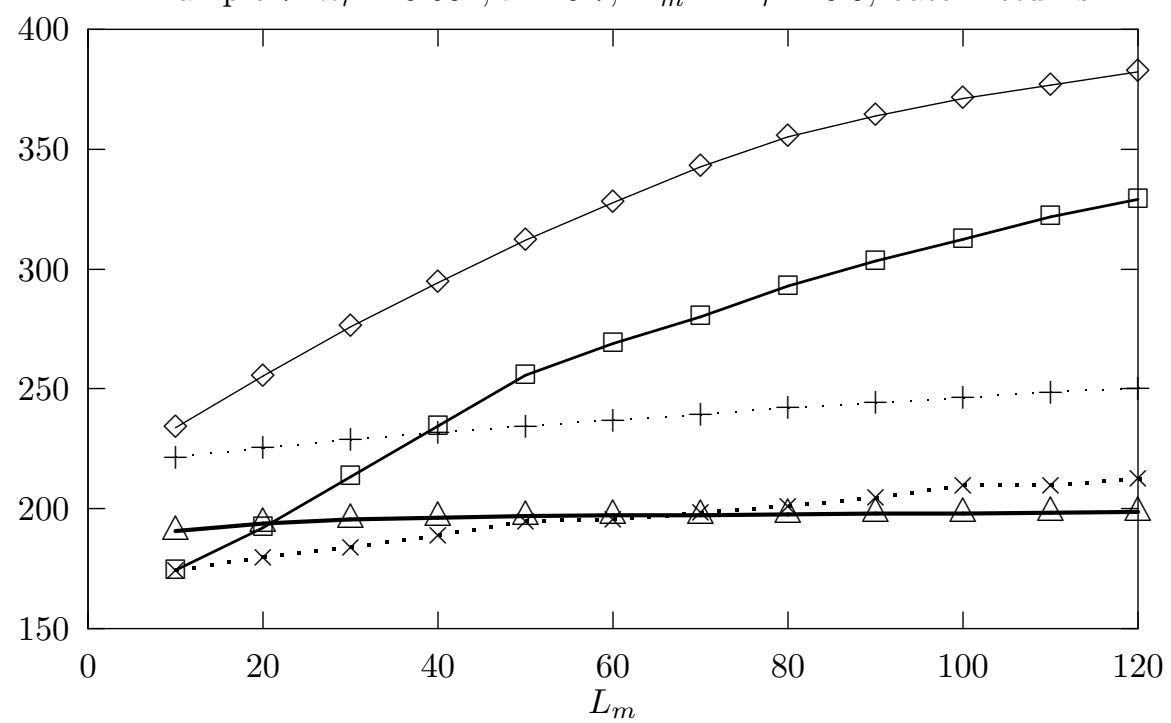

Example 8: $h_{r}=0.05, r=0.7, K_{m}=K_{r}=0.5$, batch returns

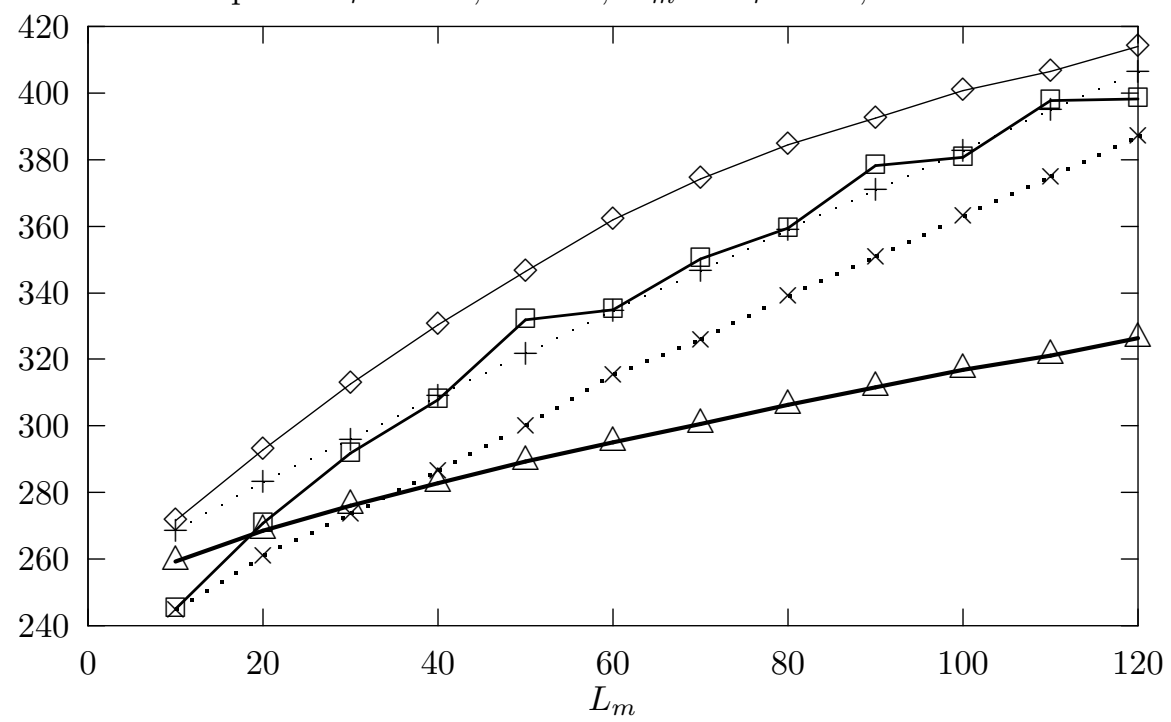

Example 9: $h_{r}=0.1, r=0.7, K_{m}=K_{r}=0.5$, batch returns

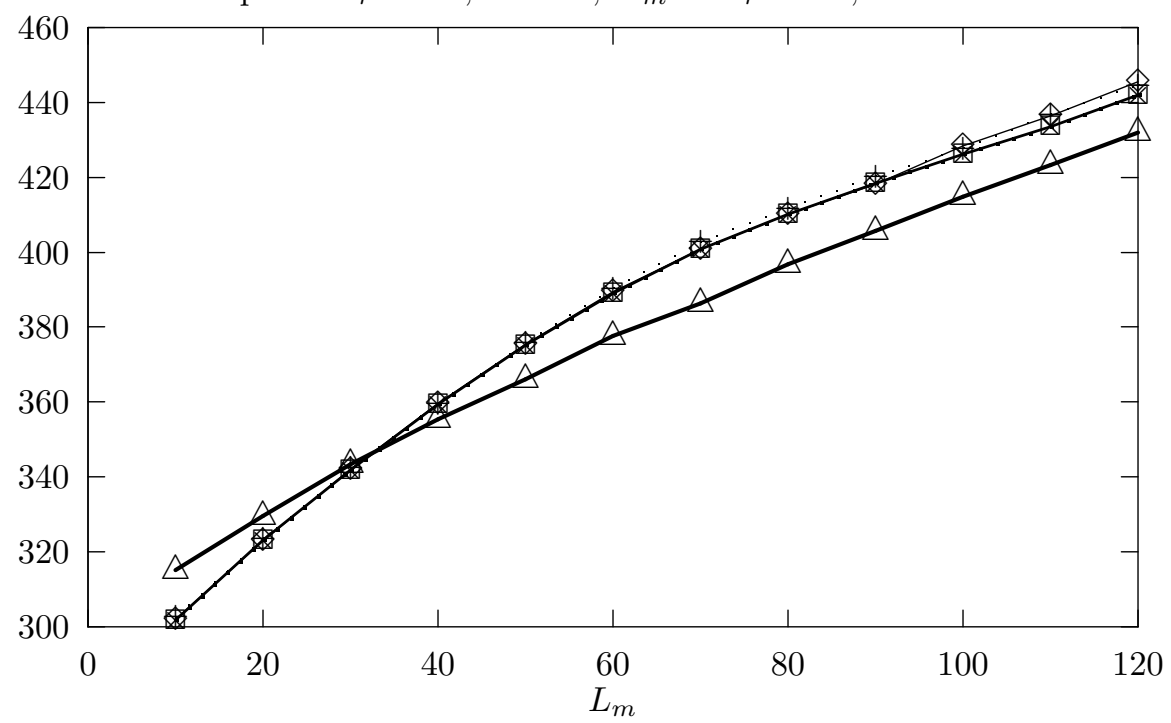

Standard PUSH $\diamond$ LT Adj. PUSH +... Standard PULL ॄ LT Adj. PULL $\cdot \times \cdot \cdot$ Separate PULL $\triangle$

Standard PUSH $\diamond$ LT Adj. PUSH +. Standard PULL $\square$ LT Adj. PULL $\times \times \cdot$ Separate PULL $\triangle$

Standard PUSH $\diamond$ LT Adj. PUSH +. Standard PULL $\square$ LT Adj. PULL $\cdot \times$. Separate PULL $\_$

Figure 9: Average costs for Examples 7-9. See Table 3 for a complete description of the model parameters. 
Example 10: $h_{r}=0.001, r=0.9, K_{m}=K_{r}=0.5$, batch returns

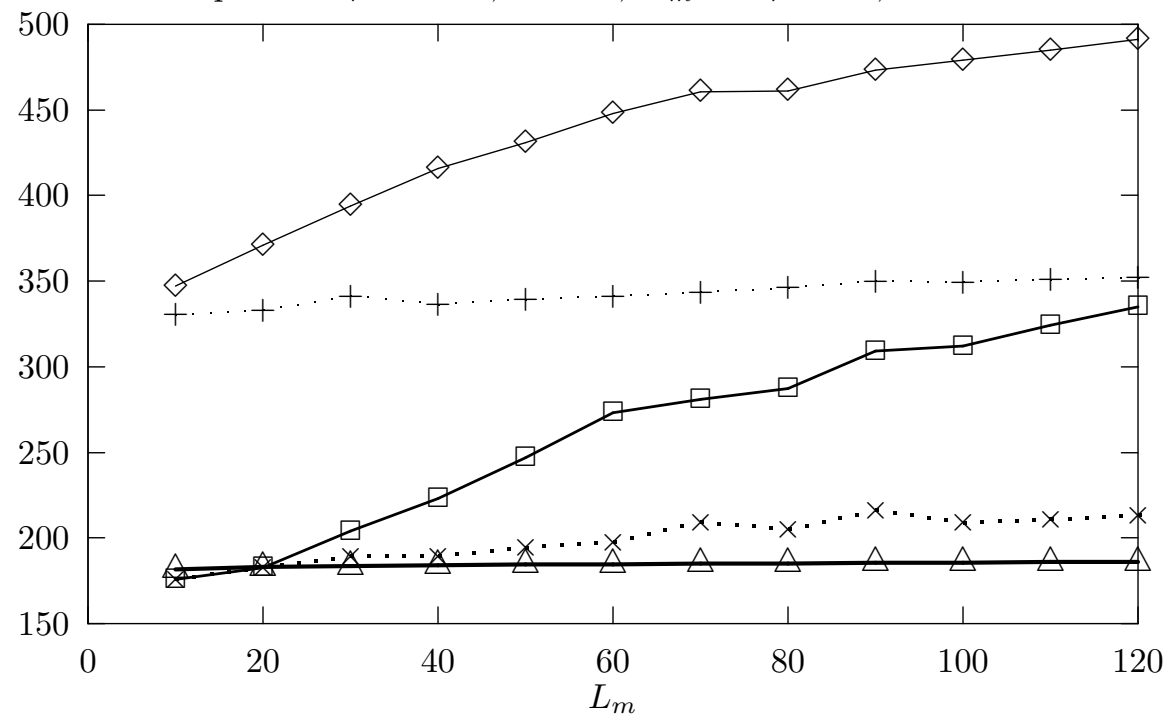

Example 11: $h_{r}=0.05, r=0.9, K_{m}=K_{r}=0.5$, batch returns

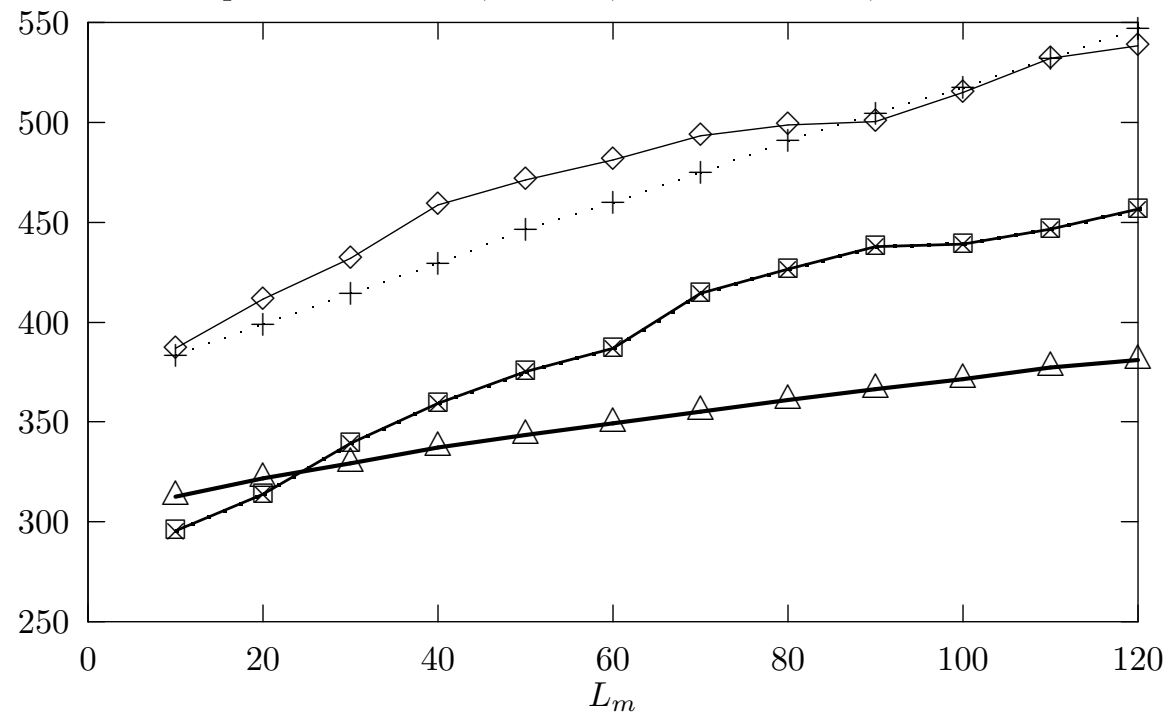

Example 12: $h_{r}=0.1, r=0.9, K_{m}=K_{r}=0.5$, batch returns

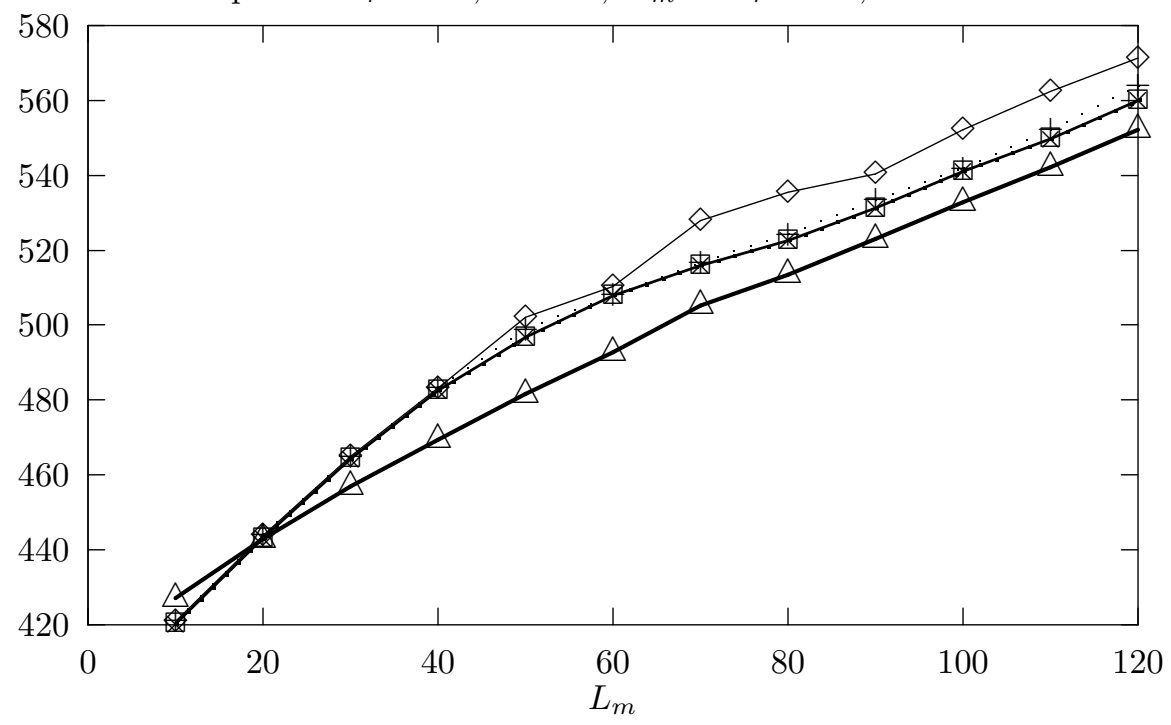

Standard PUSH $\diamond$ LT Adj. PUSH +.. Standard PULL $\square$ LT Adj. PULL ·× Separate PULL

Standard PUSH $\diamond$ LT Adj. PUSH +. . Standard PULL $\square$ LT Adj. PULL $\cdot \times \cdot-$ Separate PULL $\triangle$
Standard PUSH $\diamond$ LT Adj. PUSH +.. Standard PULL $\square$ LT Adj. PULL · $\times$. Separate PULL $\_$

Figure 10: Average costs for Examples 10-12. See Table 3 for a complete description of the model parameters. 
Example 13: $h_{r}=0.001, r=0.9, K_{m}=K_{r}=0$, unit returns

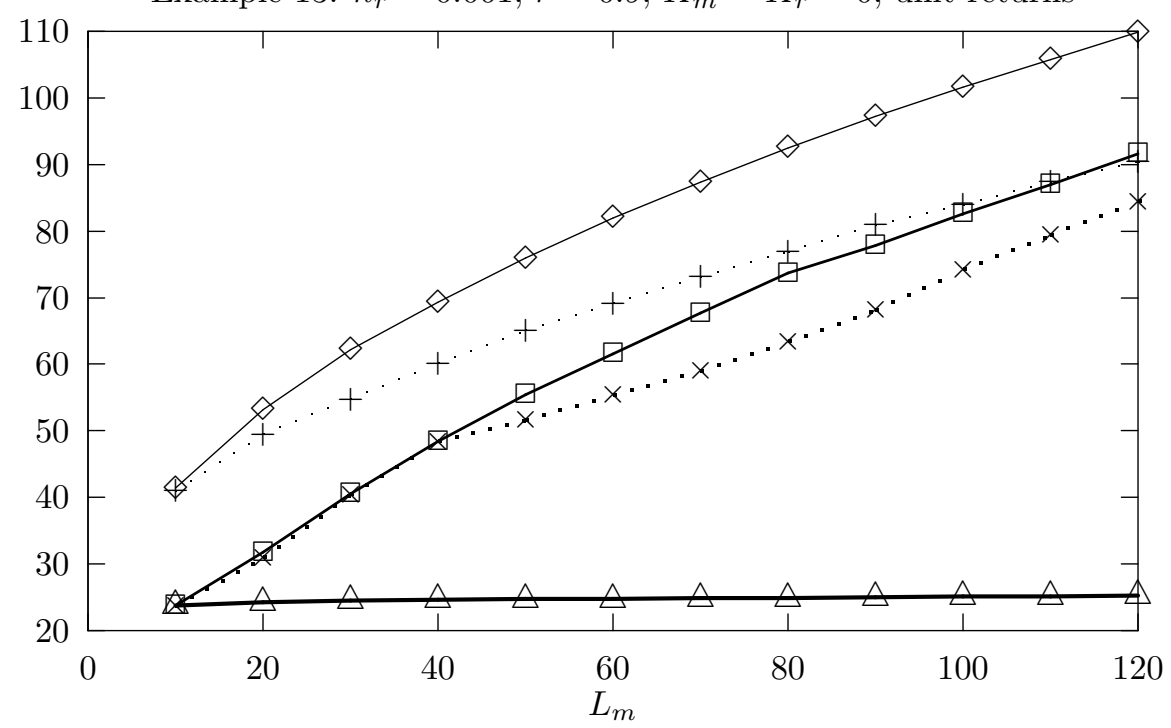

Example 14: $h_{r}=0.05, r=0.9, K_{m}=K_{r}=0$, unit returns

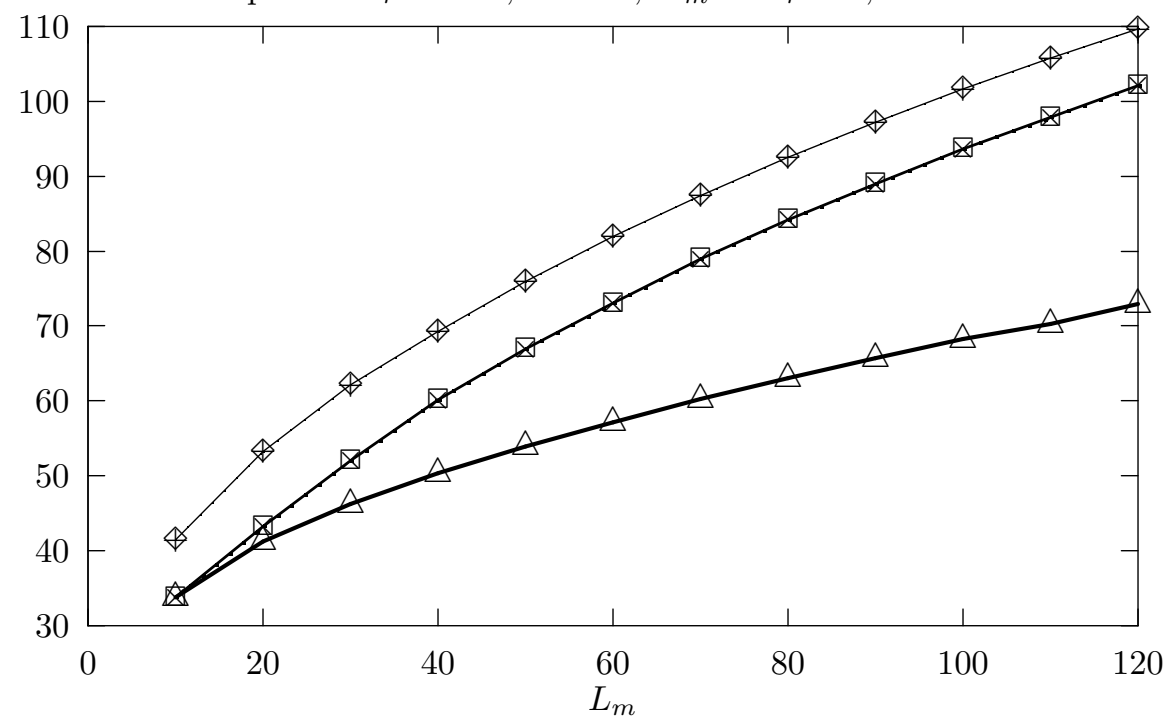

Example 15: $h_{r}=0.1, r=0.9, K_{m}=K_{r}=0$, unit returns

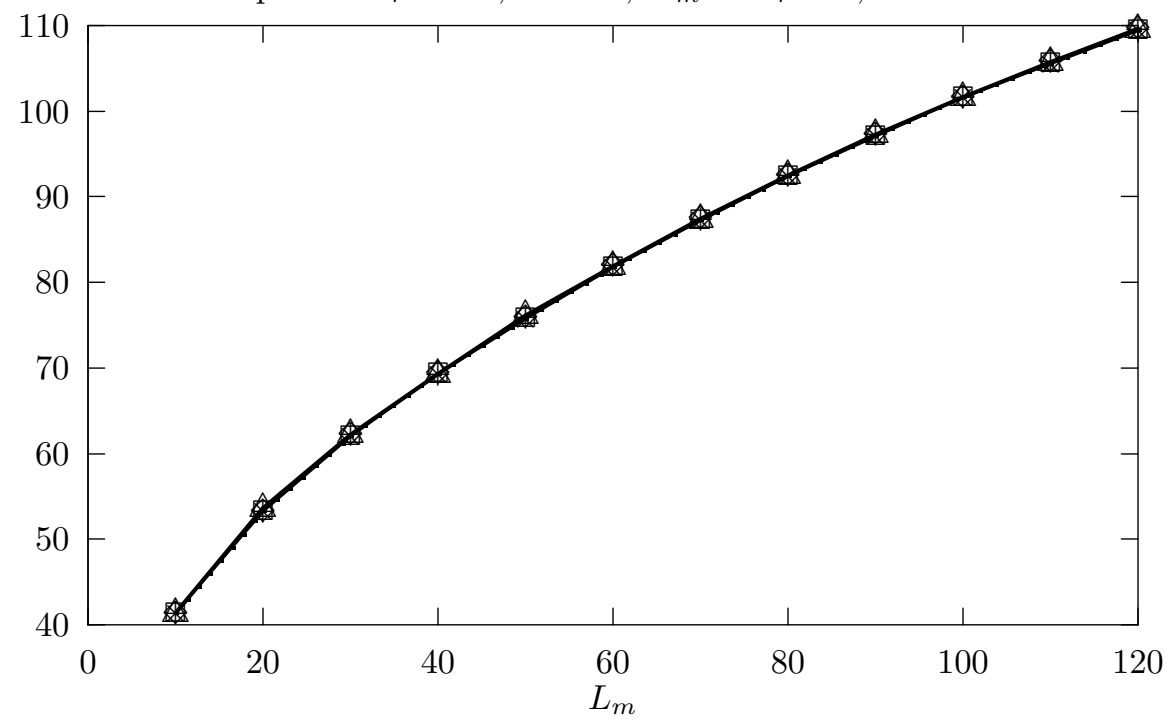

Standard PUSH $\diamond$ LT Adj. PUSH +. Standard PULL $\square$ LT Adj. PULL - $\times$. Separate PULL $\triangle$
Standard PUSH $\diamond$ LT Adj. PUSH +. . Standard PULL $\square$ LT Adj. PULL · $\times$ Separate PULL
Standard PUSH $\diamond$ LT Adj. PUSH +. Standard PULL $\square$ LT Adj. PULL $\cdot \times \cdot$ Separate PULL $\triangle$

Figure 11: Average costs for Examples 13-15. See Table 3 for a complete description of the model parameters. 


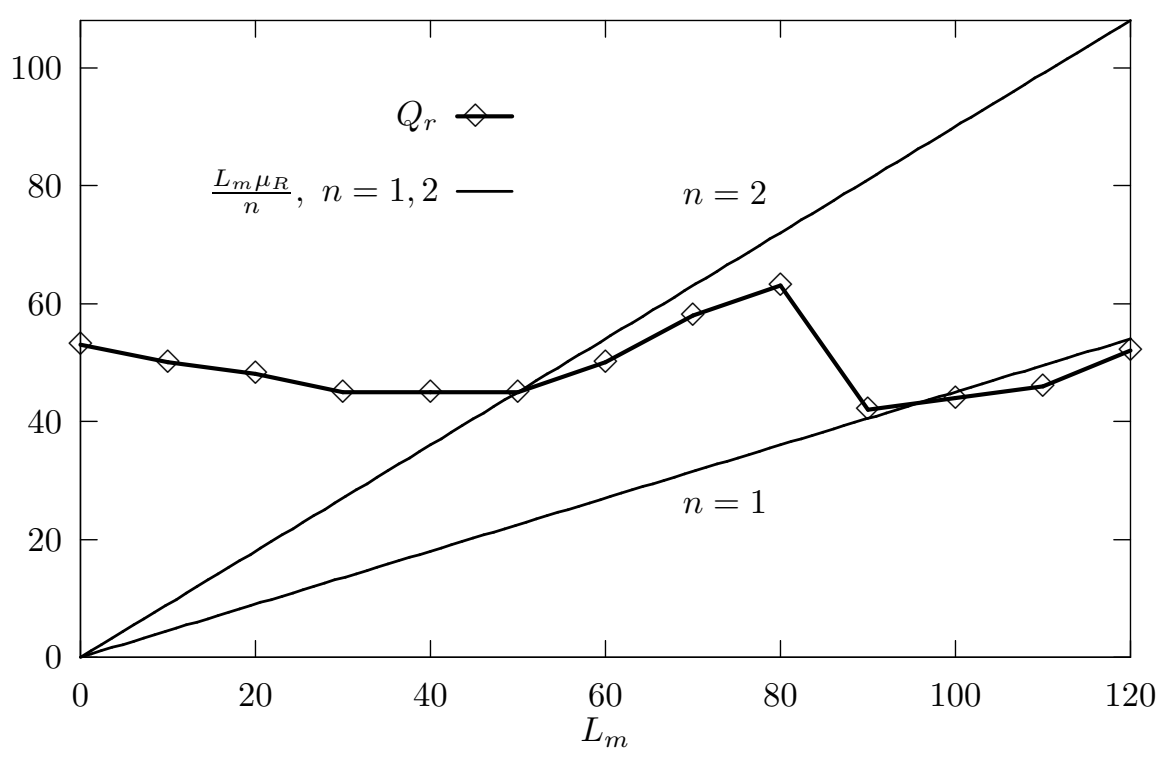

Figure 12: Illustration (for the Standard PUSH strategy in Examples 5) of 'tuning' the remanufacturing order quantity with respect to the manufacturing lead time, so that the expected number of remanufacturing cycles during a manufacturing lead time is close to some integer $n=1,2, \ldots$, i.e. $Q_{r} \approx \frac{L_{m} \mu_{R}}{n}$. This causes the 'wavy' behaviour of the optimal costs resulting from the Standard PUSH and PULL strategies in Examples 1-6.

\section{Conclusion, discussion and future research}

The main conclusion is that for hybrid inventory systems with slow manufacturing and fast manufacturing, the Separate PULL strategy that we propose performs much better than Standard PUSH and PULL or Lead Time Adjusted PUSH and PULL strategies.

An important direction for future research is to seek simple formulae that determine near-optimal values for the parameters of the Separate PULL strategy, i.e. the order levels $s_{m}$ for manufacturing and $s_{r}$ for remanufacturing, and the order quantities $Q_{m}$ for manufacturing and $Q_{r}$ for remanufacturing. Kiesmüller and Minner ${ }^{17}$ have already started this line of research, and recently proposed newsboy-type formulae $^{19}$ for the order levels. They restricted their attention to (periodic review) situations with zero set-up costs, where order quantities are not relevant. In the near future, we plan to test combinations of newsboy-type formulae for the order levels and EOQ-type formulae for the order quantities, for situations with positive set-up costs.

Another direction for future research is to test the Separate PULL Strategy in more complex inventory systems, for instance with stochastic lead times.

Finally, one can consider systems with fast manufacturing and slow remanufacturing. Also for these systems, the idea of separating manufacturing and remanufacturing decisions can be applied, but with roles reversed. The long-term remanufacturing decisions should then be based on the (traditional) inventory position. The inventory position for short-term manufacturing decisions should exclude remanufac- 
turing orders with a remaining lead time that is larger than the manufacturing lead time. This strategies could again be compared to the Standard and the Lead Time Adjusted PUSH and PULL strategies. Kiesmüller et al. ${ }^{16,20}$ have already made a comparison with the Standard PULL strategies for the special case of zero set-up costs.

\section{References}

[1] M. Thierry, M. Salomon, J. van Nunen, and L. van Wassenhove. Strategic issues in product recovery management. California Management Review, 37(2):114-135, 1995.

[2] R. Lund. Remanufacturing. Technology Review, 87(2):18-23, 1984.

[3] R. Ayres, G. Ferrer, and T. van Leynselee. Eco-efficiency, asset recovery and remanufacturing. European Management Journal, 15(5):557-574, 1997.

[4] R.B. Brayman. How to implement MRP II successfully the second time: getting people involved in a remanufacturing environment. In APICS Remanufacturing Seminar Proceedings, pages 82-88, 1992.

[5] T.E. Graedel and B.R. Allensby. Industrial Ecology. Prentice-Hall, Englewood Cliffs, New York, 1995.

[6] V.D.R. Guide, Jr. Scheduling using drum-buffer-rope in a remanufacturing environment. International Journal of Production Research, 34(9):1081-1091, 1996.

[7] J.A. Sivinski and S. Meegan. Case study: Abbott labs formalized approach to remanufacturing. In APICS Remanufacturing Seminar Proceedings, pages 27-30, 1993.

[8] E. Sprow. The mechanics of remanufacture. Manufacturing Engineering, pages 38-45, 1992.

[9] S. Vandermerwe and M.D. Oliff. Corporate challenges for an age of reconsumption. Columbia Journal of World Business, pages 7-25, 1991.

[10] R.H. Teunter. Inventory control of service parts in the final phase. PhD thesis, University of Groningen (RUG), the Netherlands, 1998.

[11] R.H. Teunter and D. Vlachos. On the necessity of a disposal option for returned products that can be remanufactured. International Journal of Production economics, to appear.

[12] E. van der Laan. The effects of remanufacturing on inventory control. PhD thesis, Erasmus University Rotterdam, the Netherlands, 1997.

[13] E.A. van der Laan, M. Salomon, R. Dekker, and L.N. van Wassenhove. Inventory control in hybrid systems with remanufacturing. Management Science, 45(5):733-747, 1999. 
[14] K. Inderfurth and E. van der Laan. Leadtimes effects and policy improvement for stochastic inventory control with remanufacturing. Preprint No. 22, Faculty of Economics and Management, Otto-vonGuericke University of Magdeburg, Magdeburg, Germany, 1998.

[15] V.D.R. Guide, Jr. Production planning and control for remanufacturing: industry practise and research needs. Journal of Operations Management, 18(4):467-483, 2000.

[16] G.P. Kiesmüller. A new approach for controlling a hybrid stochastic manufacturing/remanufacturing system with inventories and different lead times. Working paper, Eindhoven University of Technology, Faculty of Technology Management, 2001.

[17] G.P. Kiesmüller and S. Minner. Simple expressions for finding recovery system inventory control parameters. Working paper, Eindhoven University of Technology, Faculty of Technology Management, 2001.

[18] R.H. Teunter, E. van der Laan, and K. Inderfurth. How to set the holding cost rates in average cost inventory models with reverse logistics? OMEGA The International Journal of Management Science, 28:409-415, 2000.

[19] E.A. Silver, D.F. Pyke, and R. Peterson. Inventory Management and Production Planning and Scheduling. John Wiley and Sons, New York, 1998.

[20] G.P. Kiesmüller and A.G. de Kok. Reducing production variability in a hybrid stochastic manufacturing/remanufacturing system. Working paper, Eindhoven University of Technology, Faculty of Technology Management, 2001.

Acknowledgement: The research presented in this paper is part of the research on re-use in the context of the EU sponsored TMR project REVersed LOGistics (ERB 4061 PL 97-5650) in which participate: the Erasmus University Rotterdam (NL), the Eindhoven University of Technology (NL), the Otto-vonGuericke Universitaet Magdeburg (D), INSEAD (F), the Aristoteles University of Thessaloniki (GR) and the University of Piraeus (GR). 


\section{Publications in the Report Series Research ${ }^{*}$ in Management}

ERIM Research Program: "Business Processes, Logistics and Information Systems"

\section{2}

The importance of sociality for understanding knowledge sharing processes in organizational contexts Niels-Ingvar Boer, Peter J. van Baalen \& Kuldeep Kumar ERS-2002-05-LIS

Crew Rostering for the High Speed Train

Ramon M. Lentink, Michiel A. Odijk \& Erwin van Rijn

ERS-2002-07-LIS

Equivalent Results in Minimax Theory

J.B.G. Frenk, G. Kassay \& J. Kolumbán

ERS-2002-08-LIS

An Introduction to Paradigm

Saskia C. van der Made-Potuijt \& Arie de Bruin

ERS-2002-09-LIS

Airline Revenue Management: An Overview of OR Techniques 1982-2001

Kevin Pak \& Nanda Piersma

ERS-2002-12-LIS

Quick Response Practices at the Warehouse of Ankor

R. Dekker, M.B.M. de Koster, H. Van Kalleveen \& K.J. Roodbergen

ERS-2002-19-LIS

Harnessing Intellectual Resources in a Collaborative Context to create value

Sajda Qureshi, Vlatka Hlupic, Gert-Jan de Vreede, Robert O. Briggs \& Jay Nunamaker

ERS-2002-28-LIS

Version Spaces and Generalized Monotone Boolean Functions

Jan C. Bioch \& Toshihide Ibaraki

ERS-2002-34-LIS

Periodic Review, Push Inventory Policies for Remanufacturing

B. Mahadevan, David F. Pyke, Moritz Fleischman

ERS-2002-35-LIS

Modular Decomposition of Boolean Functions

Jan C. Bioch

ERS-2002-37-LIS

Classification Trees for Problems with Monotonicity Constraints

R. Potharst \& A.J. Feelders

ERS-2002-45-LIS

\footnotetext{
A complete overview of the ERIM Report Series Research in Management: http://www.ers.erim.eur.nl

ERIM Research Programs:

LIS Business Processes, Logistics and Information Systems

ORG Organizing for Performance

MKT Marketing

F\&A Finance and Accounting

STR Strategy and Entrepreneurship
} 
Allocation of Railway Rolling Stock for Passenger Trains

Erwin Abbink, Bianca van den Berg, Leo Kroon \& Marc Salomon

ERS-2002-47-LIS

Monotone Decision Trees and Noisy Data

Jan C. Bioch and Viara Popova

ERS-2002-53-LIS

Business Modeling Framework For Personalization In Mobile Business Services: a Case and Sociological Analysis L-F Pau, Jeroen Dits

ERS-2002-56-LIS

Polynomial time algorithms for some multi-level lot-sizing problems with production capacities Stan van Hoesel, H. Edwin Romeijn, Dolores Romero Morales, Albert P.M. Wagelmans ERS-2002-59-LIS

A Note on Ending Inventory Valuation in Multiperiod Production Scheduling

Wilco van den Heuvel, Alfred P.M. Wagelmans

ERS-2002-63-LIS

Determining The Optimal Order Picking Batch Size In Single Aisle Warehouses

Tho Le-Duc and René B.M. de Koster

ERS-2002-64-LIS

Solving Variational Inequalities Defined on A Domain with Infinitely Many Linear Constraints

Shu-Cherng Fang, Soonyi Wu, Ş. Illker Birbil

ERS-2002-70-LIS

Entropic Regularization Approach for Mathematical Programs with Equilibrium Constraints

Ş. Illker Birbil, Shu-Cherng Fang, Jiye Han

ERS-2002-71-LIS

On the Finite Termination of An Entropy Function Based Smoothing Newton Method for Vertical Linear Complementarity Problems

Shu-Cherng Fang, Jiye Han, Zhenghai Huang, Ş. Illker Birbil

ERS-2002-72-LIS

The Role Of Product Quality Information, Market State Information And Transaction Costs In Electronic Auctions Otto Koppius and Eric van Heck

ERS-2002-73-LIS

Shunting of Passenger Train Units in a Railway Station

Richard Freling, Ramon M. Lentink, Leo G. Kroon, Dennis Huisman

ERS-2002-74-LIS

Inventory strategies for systems with fast remanufacturing

Ruud Teunter, Erwin van der Laan, Dimitrios Vlachosz

ERS-2002-77-LIS

A Business Evaluation Of The Next IPv6 Protocol In Fixed And Mobile Communication Services: An Analytical Study And Calculation

L-F Pau

ERS-2002-78-LIS

IPv6 Return on investment (R.O.I) analysis framework at a generic level, and first conclusions

L-F Pau

ERS-2002-79-LIS 
On Borel Probability Measures and Noncooperative Game Theory J.B.G.Frenk, G.Kassay, V.Protassov

ERS-2002-85-LIS 